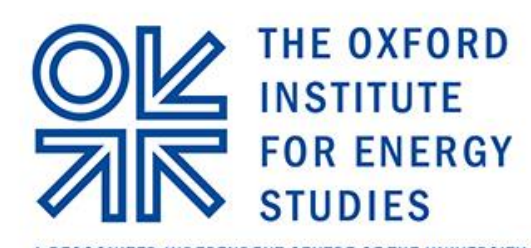

A RECOGNIZED INDEPENDENT CENTRE OF THE UNIIERSITY OF OXFORD

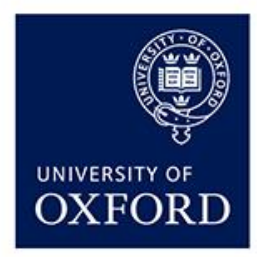

June 2016

\title{
Business model for cross-border interconnections in the Mediterranean basin
}

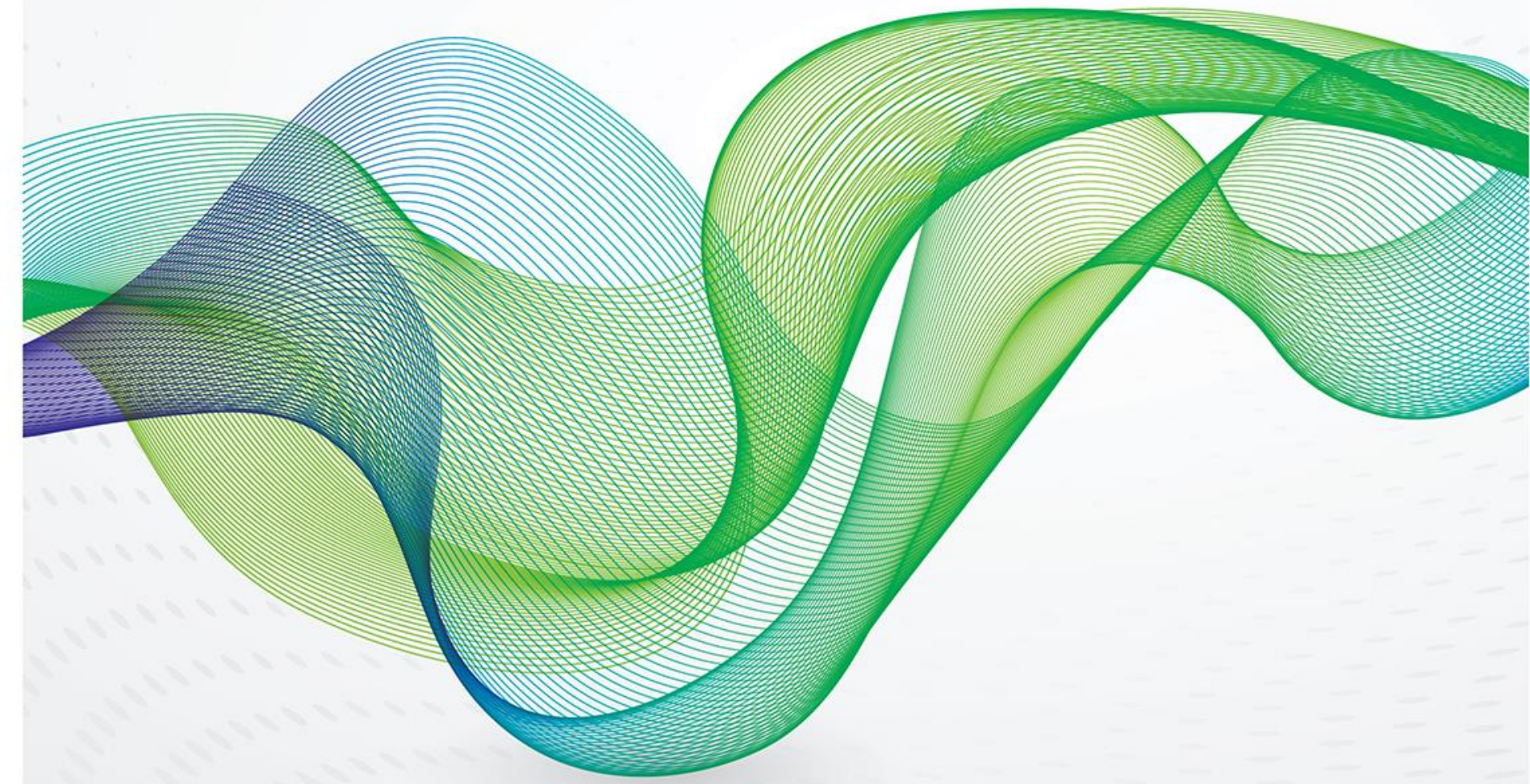



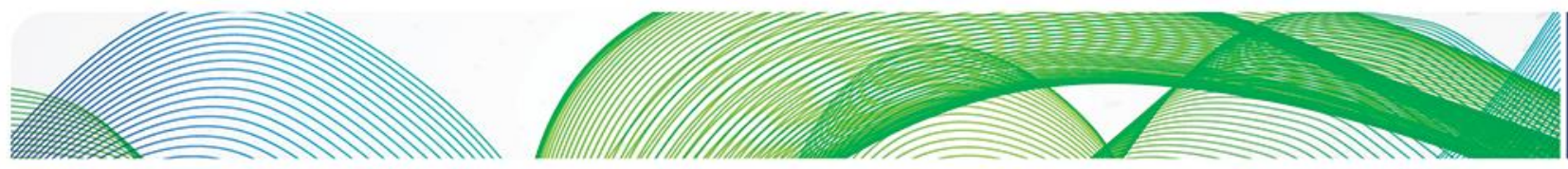

\section{잊조}

The contents of this paper are the authors' sole responsibility. They do not necessarily represent the views of the Oxford Institute for Energy Studies or any of its members.

Copyright $\odot 2016$

Oxford Institute for Energy Studies

(Registered Charity, No. 286084)

This publication may be reproduced in part for educational or non-profit purposes without special permission from the copyright holder, provided acknowledgment of the source is made. No use of this publication may be made for resale or for any other commercial purpose whatsoever without prior permission in writing from the Oxford Institute for Energy Studies.

ISBN 978-1-78467-059-7 


\section{Contents}

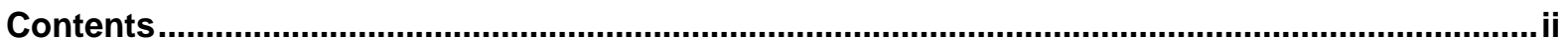

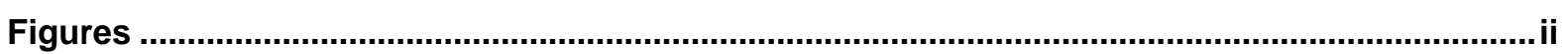

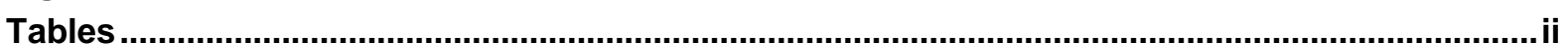

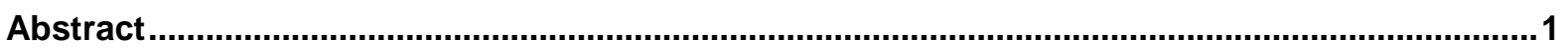

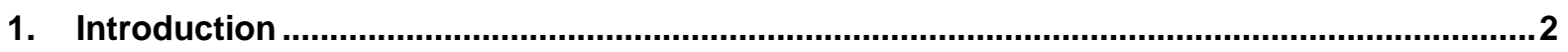

2. Energy scenario in the region (demand and supply) ...........................................................

3. Existing and planned interconnection in the Euro-Mena region ...........................................6

3.1 Investment in IC infrastructures in the MENA region: An assessment ................................. 7

4. The interconnection investment models .............................................................................11

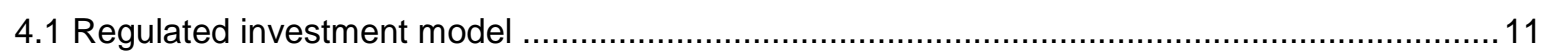

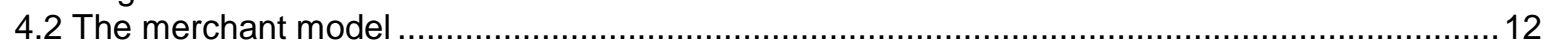

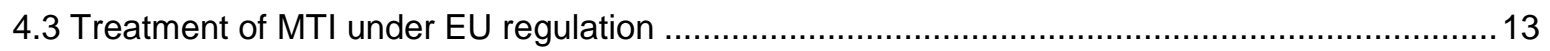

5. Regulatory framework for a viable interconnection business model ....................................16

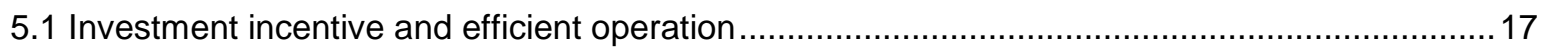

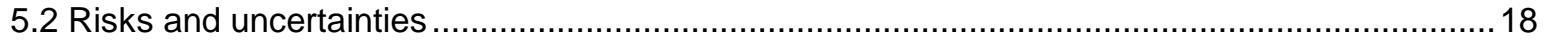

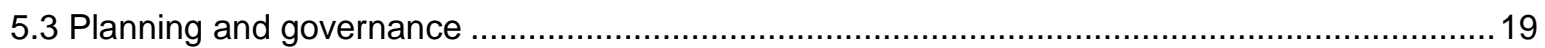

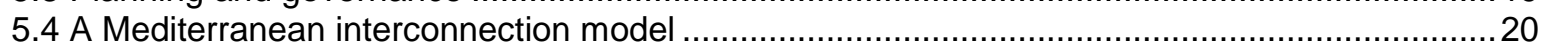

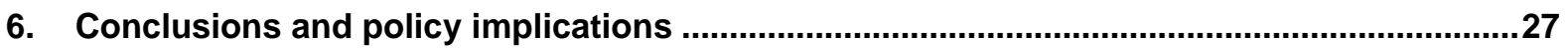

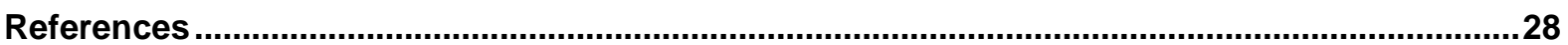

\section{Figures}

Figure 1: Gross domestic product, constant prices and percent change .................................... 4

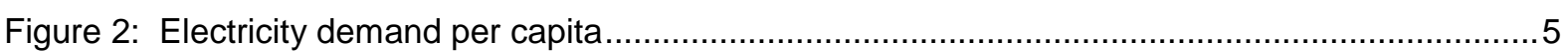

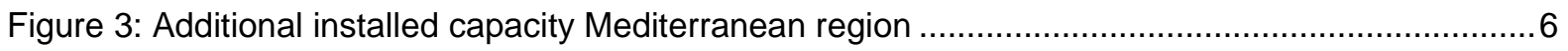

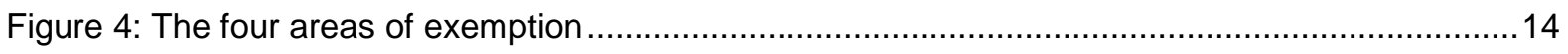

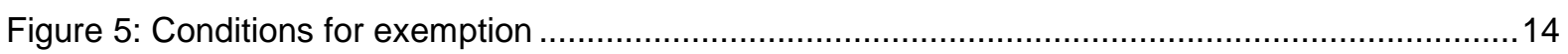

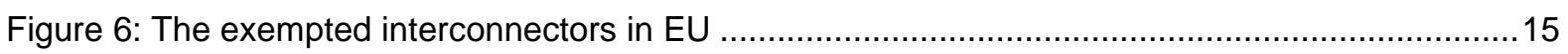

Figure 7: The main elements of a viable business model for interconnection investment .................17

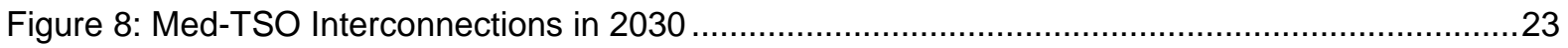

\section{Tables}

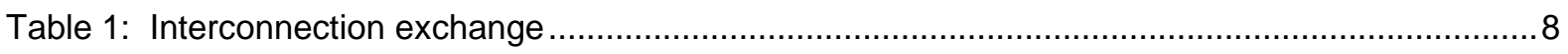

Table 2: Planned interconnections in the SEMCs ............................................................... 10

Table 3: Key characteristics under regulated versus merchant interconnector ...............................13

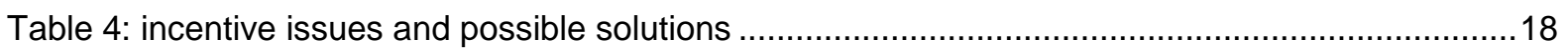

Table 5: Advantages and disadvantages of investment models in interconnections ........................26

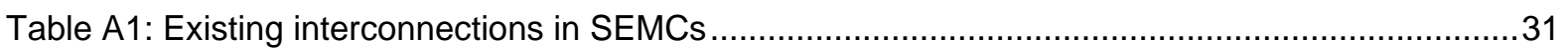




\title{
Business model for cross-border interconnections in the Mediterranean basin
}

\author{
Rahmatallah Poudineh \\ Senior research fellow, Oxford Institute for Energy Studies \\ Email: rahmat.poudineh@oxofrdenergy.org \\ Alessandro Rubino \\ Research Fellow in Economics, University of Bari \\ Email: alessandro.rubino@eui.eu
}

\begin{abstract}
The complementarity between electricity systems of the north and south Mediterranean basin along with the need for diversification of energy resources and optimisation of energy systems are among the reasons for greater electricity trade and cross-border integration in the region. However, development of cross-border interconnection in the Mediterranean basin requires a business model which provides incentives for investment and efficient operation, manages risks and uncertainties and facilitates coordinated planning and governance. We contend that, due to high perceived risk of investment, delivery of interconnection projects through the EU regulated model is less likely, or only possible at prohibitively high rate of returns. The merchant transmission initiative (MTI), on the other hand, is seen as an exception under the EU laws and can be approved only if the project meets a set of strict conditions. We, therefore, advocate a hybrid business model in which the main benefits of a merchant model are maintained within a regulated structure. We highlight the main components of the proposed business model and show how it addresses the key features of a viable business model in relation to incentives, risks and governance. Our analysis demonstrates that the proposed Mediterranean business model for interconnection can better provide incentives for investment and is more compatible with the region's energy scenario, governance structure and the risk attitude.
\end{abstract}

Keywords: Interconnection, business model, Mediterranean basin, regulatory framework, MTI

JEL Classification: L43, L51, L94, K23 

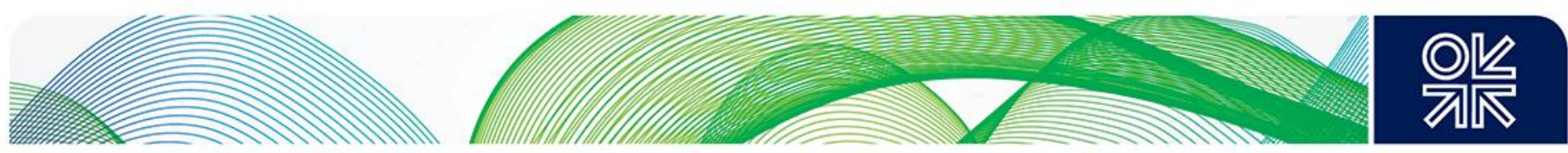

\section{Introduction}

The existing Mediterranean energy infrastructure was mostly designed and built more than 50 years ago and were based on the national-level energy policies and security of supply priorities of the time. Since then, the energy landscape has changed dramatically. Now, national dynamics must be harmonised with regional and global developments and policies. In particular, climate change policies and energy security measures have greatly impacted the existing energy infrastructures and transmission grids, and are expected to continue doing so in the foreseeable future. In order to achieve the national and regional energy policy objectives, the infrastructural endowment will need to be updated in most countries of the region. For the electricity grid, a combination of short-term goals and long-term patterns will guide development of the transmission network in the coming decades. Reinforced interconnection between Member States (MS) in the EU and South and East Mediterranean Countries ${ }^{1}$ (SEMCs) are required in order to achieve more secure and more sustainable energy systems. This is also compatible with other energy policy objectives. For example, the EU member states are required to comply with the completion of an integrated Internal Energy Market (IEM) by 2020.

From an economic perspective, development of the interconnection in the Mediterranean region requires a business model that not only addresses the common regulatory challenges of grid infrastructures, such as incentive for investment and efficient operations, but also takes into account the risk and heterogeneities among the countries of the region. There is a sharp difference between the North Mediterranean Countries (NMCs) and SEMCs in terms of stage of development, power sector structure, market openness and maturity, regulations and institutions and political stability. These differences have manifested themselves in different energy needs and regulatory priorities in relation to the energy trilemma of affordability, reliability and sustainability. Europe emphasises interconnections among MS in order to achieve the 10\% electricity interconnection target envisaged by the Barcelona European Council in 2002 and reinforced in the recent Energy Union communication (European Commission, 2015). For SEMCs the greatest challenge, however, is to accommodate existing and future demand with the inevitable repercussion that these dynamics will have on transmission network and interconnections.

The cross-border interconnections, as other capital-intensive networks, are natural monopolies and traditionally they have operated under incentive regulation, a regulatory paradigm which still constitutes the main business model for interconnections in the EU region. However, the EU regulated investment model has been unable to unlock investment in cross-border interconnection. The insight from economics theory that regulators can encourage competition "for the market" where competition "in the market" is not feasible attracted interest in a new business model known as Merchant Transmission Initiative (MTI). Under this model, private investors enter the market with the incentive that they will be exempted (fully or partially) from the regulatory restrictions which prevail under the regulated model. Nonetheless, the MTI model is considered an exception to the EU laws, and private investors still face various other challenges investing in interconnection in a heterogeneous region.

This paper analyses the issue of interconnection development in the Mediterranean basin and highlights the challenges of the EU model to facilitate investment. We charecterise the specifications of a viable business model for interconnectors in the region and propose a hybrid approach, with the aim to minimize market risks to investors while improving security of supply. In our model, the interconnections will initially be developed to export excess electricity capacity from Europe to North Africa, but it is

${ }^{1}$ Algeria, Egypt, Libya, Morocco, Tunisia, Turkey, Israel, Jordan, Lebanon, Palestine, and Syria.

Business model for cross-border interconnections in the Mediterranean basin 

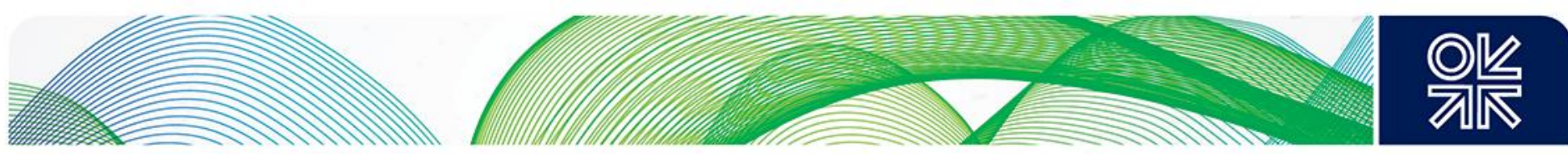

flexible to adapt to any development of the regions' electricity mix in the future. Furthermore, the suggested business model operates with minimal regulatory changes needed in the domestic markets. We acknowledge the presence of political instability in some of the countries of the southern Mediterranean region and do not assume that interconnections will help to alleviate them ${ }^{2}$. The presence of political instability will lead to increased risk premiums and consequently higher cost of capital in the country considered. The model is designed such that the business risk is shared efficiently among the parties involved.

The next section discusses energy scenarios in the Mediterranean region and its implications for electricity grid infrastructures. Section 3 assesses the state of the existing and planned interconnectors in the Mediterranean region. Section 4 discusses the main economic properties of regulated investment model vis a vis MTI and presents the substantive treatment of MTI under the EU regulation. The regulatory framework for a viable business model for cross-border interconnection is discussed in section 5 . Section 6 is conclusions.

\section{Energy scenario in the region (demand and supply)}

Despite its long history of interactions, the Mediterranean today is a highly fragmented region that is facing unprecedented social, economic and political challenges. The events associated with the socalled "Arab spring" 3 that started in 2011 are deeply connected with a process of democratization of the civil societies and with the unbalanced distribution of wealth and opportunities at national and regional levels. The region, in fact, is characterised by economic inequity, extending from the affluent north basin ${ }^{4}$ to the areas of deep poverty and scarcity of resources in the south and east of the basin ${ }^{5}$, where the demographic rate is increasing faster. The regional distribution of Gross Domestic Product (GDP) and population today along with projections for these trends point to diverging socio-economic development.

South and East Mediterranean Countries (SEMCs) that currently account for just above $25 \%$ of the total GDP of the region are expected to grow at twice the rate of the North Mediterranean Countries (NMCs) (see Figure 1). In 2030, SEMCs will account for around one-third of the region's total GDP. In terms of population a similar trend exists: the population is growing at a faster rate in the SEMCs than the north, and by $203060 \%$ of the population will be in countries on the south shore of the basin (OME, 2015).

\footnotetext{
${ }^{2}$ Political instability in the SEMCs depends on various factors mostly related to the macroeconomic and social sphere, and have adverse implications for the business climate in the region.

${ }^{3}$ See Roy (2012), for a comprehensive review and analysis.

${ }^{4}$ For the purposes of our analysis we follow OME classification and include as North Mediterranean Countries (NMCs) both EU countries (Cyprus, France, Greece, Italy, Malta, Portugal, Slovenia, Spain) and non-EU countries (Albania, Bosnia Herzegovina, Croatia, FYROM, Serbia)

${ }^{5}$ Algeria, Egypt, Libya, Morocco, Tunisia, Turkey, Israel, Jordan, Lebanon, Palestine, Syria.
} 

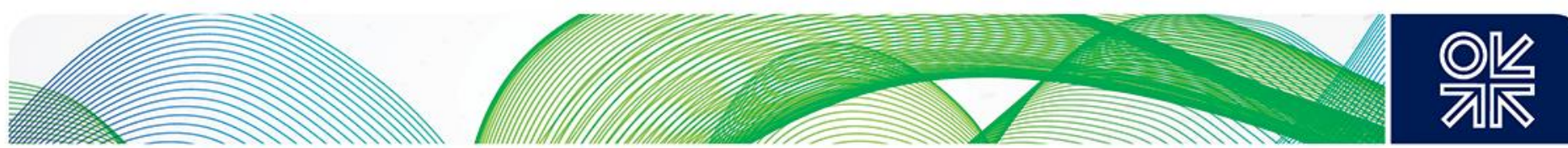

Figure 1: Gross domestic product, constant prices and percent change

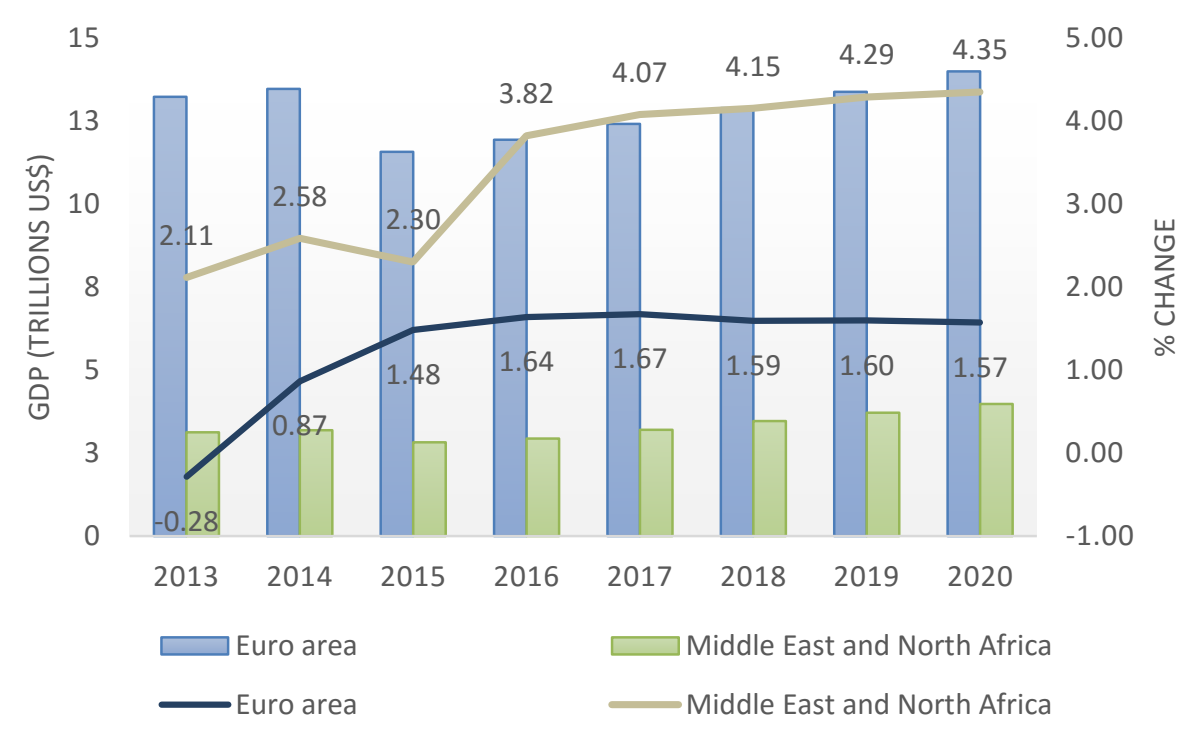

Source: International Monetary Fund, World Economic Outlook Database, October 2015

The energy balance and regional trade flows will be significantly affected by these imbalances. Since energy demand in developing countries is correlated with GDP trends, it is expected that future demand will increase in the Middle East and North African countries (MENA). At the same time, weak growth, the declining population trends, high retail electricity prices to recover the cost of public policies and the effective deployment of energy efficiency measures shall all contribute to reducing electricity consumption on the European side of the Basin. Nevertheless, despite this projected convergence, MENA countries in 2020 will still consume just half the electricity as the north on a per capita basis (see Figure 2). In addition, notwithstanding most countries have close to $100 \%$ access to electricity, there is part of the population that either still lack access to electricity or suffers from scarce or insufficient electricity supply, especially in rural areas and in informal settlements ${ }^{6}$.

The projected GDP and demographic trend as well as rapid urbanisation have an immediate effect on the supply and demand for electricity services. They elevate pressure on the existing infrastructure and increase the necessity of new investments. The World Bank in $2010^{7}$ estimated that the region needs investments in excess of $€ 27$ billion a year (US $\$ 30$ billion) up to 2040 . This number represents about $3 \%$ of the region's total projected GDP, and implies a rate of investment three times higher than the rest of the world. This staggering amount is required, according to the World Bank, to deal with a number of key issues that, at present, reduce the attractiveness of the energy sector in the region. Reduced subsidies for fossil fuel consumption, environmental protection, additional generation capacity and the promotion of intra-regional cross-border energy trade are all envisioned to be an important part of the solution to the region's energy challenges.

\footnotetext{
${ }^{6} 20$ million people in the region are without access to electricity, while at least 12 million use traditional biomass for cooking and heating (REN21, 2013, p.30).

7 These reference figures are highly cited. It comes from a background document accessible via the following link: http://go.worldbank.org/88TPPX6OF0 (the entire document is not accessible anymore).
}

Business model for cross-border interconnections in the Mediterranean basin 

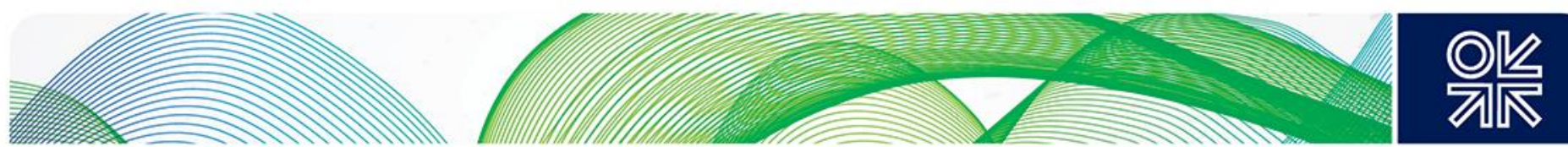

Figure 2: Electricity demand per capita

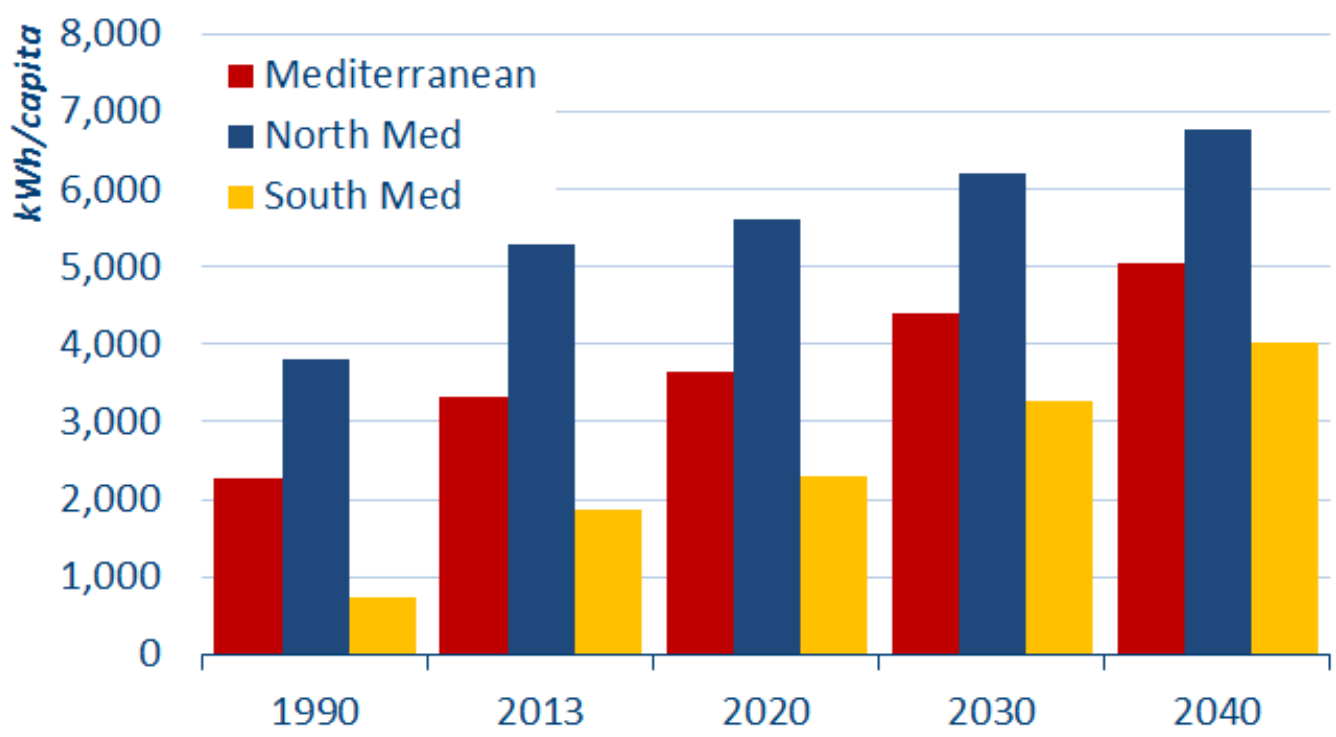

Source: OME 2015

More recently the Observatoire Mediterranéèn de l'Energie, in 2015, estimated that over $€ 715$ billion will be needed by 2030 to meet additional generation needs. This level of investment is in line with figures that forecast the installation of $446 \mathrm{GW}$ of natural gas-fired power plants by 2040, from $202 \mathrm{GW}$ in 2013, of which 280 GW would be in the South and East Mediterranean, from 86 GW in 2013. Renewables also are expected to play an important role and will account for $449 \mathrm{GW}$ of installed capacity in 2040 (105 GW in the South and East Mediterranean), of which 331 GW is non-hydro (61 GW in the South and East Mediterranean). Most of the generation capacity additions foreseen in the region will be installed in the South and East (313 GW, including nuclear) while $218 \mathrm{GW}$ will be installed in the North, mostly from renewable energy sources (RES) (see Figure 3).

The increased generation fleet and the significant penetration of RES generation, on both sides of the basin, requires not only the strengthening and integration of the Southern Mediterranean networks but also their integration with the Northern ones. The association of the Mediterranean TSOs ${ }^{8}$ (MED-TSO) is expecting the construction of an additional $33000 \mathrm{~km}$ of high voltage lines and at least $3000 \mathrm{MW}$ of North-South Interconnections. MED-TSO estimated the investment required, for the additional transport capacity, to be in the order of $€ 20$ billion by 2020 (Med-TSO, 2013).

\footnotetext{
${ }^{8}$ In 2013, Med-TSO started its activity. Med-TSO includes electricity companies operating the grids of 17 Mediterranean Countries.
}

Business model for cross-border interconnections in the Mediterranean basin 

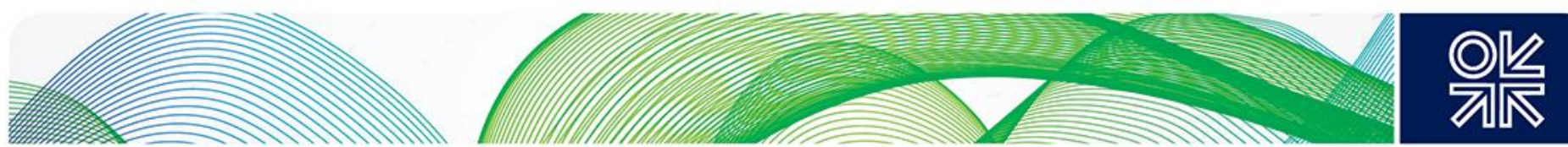

Figure 3: Additional installed capacity Mediterranean region

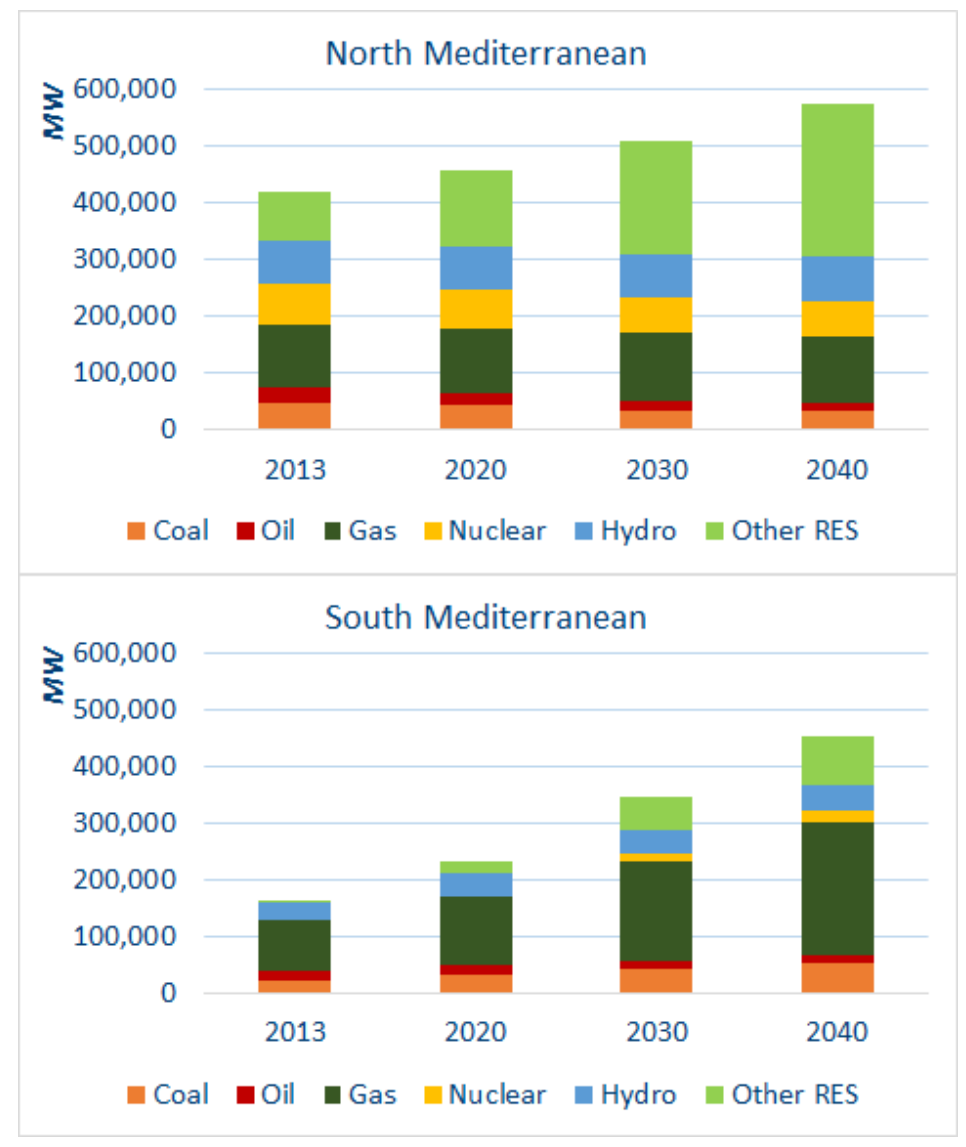

Source: OME 2015

\section{Existing and planned interconnection in the Euro-Mena region}

As discussed in Rubino and Cuomo (2015), the significant interdependencies and complementarities across the Mediterranean basin could justify the development of interconnection infrastructures (IC). In the current situation (with unused excess generation in the north and strong demand growth in the south), IC may be a valid substitute (or at least complement) for investment in additional generation capacity. Cross-border transmission lines are also considered a pre-requisite for the creation of a wellintegrated energy market and can foster market integration. Although state-level energy policies are still very important and strategic, it is indisputable and well established in the literature that modern energy dynamics extend well beyond national borders. Therefore, there is a combination of domestic, regional and global factors that underpin the analysis of the regulatory framework for electricity interconnection (see Cambini and Rubino, 2015). Although highly relevant for electricity market integration, interconnections are, at present, scarce in Europe (European Commission, 2007 p. 174; European Climate Foundation, 2010 p. 93). The case is even stronger when we look at the available interconnection in the Mediterranean basin. Currently, there are four synchronous areas around the 

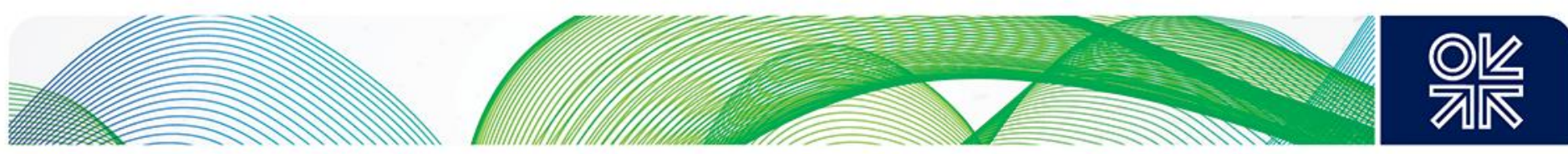

Mediterranean basin. These are a) the European continental network, which is connected to the North West Maghreb countries via the Spain-Morocco cable, b) the North East Maghreb block connected with the Mashreq ${ }^{9}$ countries, c) the system including Palestine and Israel and d) the network of Turkey (MED-EMIP, 2010). The only existing transmission lines linking EU and non-EU countries are those connecting Spain with Morocco and a limited interconnection between Turkey and Bulgaria as well as Turkey and Greece.

A number of studies have simulated the interconnection expansion expected (or at least economically viable) in the Euro-Mediterranean basin (see L'Abbate et al., 2014; Trieb et al., 2009, Med EMIP, 2010). Depending on the set-up considered and on the generation cost assumptions, several possible scenarios have emerged out of these simulations. According to L'Abbate et al. (2014), under the "Pessimistic" scenario 2400 MW of interconnection capacity is considered along three routes ${ }^{10}$. Whereas under the "Reference" and "Optimistic" scenarios, the foreseen level of cross-border interconnection increases considerably to $6000 \mathrm{MW}$ or $10000 \mathrm{MW}^{11}$ of total IC capacity respectively. However, while the economic rationale suggests that the current and expected market fundamentals justify IC investment in the region, the existing state of affairs are at a significant distance from this theoretical benchmark (see Tholens, 2014; Cambini and Rubino, 2015, Somma and Rubino, 2016).

In the remainder of this section we provide an overview of the existing and planned investment projects in cross-border interconnection in the region. While most modelling exercises generally conclude that in the presence of favourable economic conditions investment will proceed, our review highlights the regulatory and institutional obstacles that might impede (or slow down) the development of the planned cross-border interconnections.

\subsection{Investment in IC infrastructures in the MENA region: An assessment}

After two decades of regulatory practice, it is now clear that institutional diversity and the existing legal and regulatory framework play a fundamental role in explaining the volumes of energy exchange between countries, vis a vis price differential. Notwithstanding the recent progress towards global economic and financial integration, national borders in the Mediterranean area still show a significant and depressing effect on energy trade. This is even more evident in the south-south route when we look at electricity trade, where physical connection is already in place but the rate of utilisation of the existing capacity is extremely low (please refer to Table 1). North-south interconnection is even more limited, consisting of just the Spain-Morocco interconnection.

Nonetheless, the Spain-Morocco interconnection is the most used interconnection in the region (in terms of energy exchange) with a high load factor which is consistently exporting excess capacity from Spain toward North Africa. The fact that intra-regional interconnections are barely used signals that interconnection investment in the southern region is driven by security of supply rather than the market. It also shows the funadmematal problem of the absence of shared rules and trust among SEMCs countries $^{12}$. These factors cannot be disregarded when defining a viable Mediterranean business model of interconnection. In the short to medium term, the EU's excess capacity can be used to develop

\footnotetext{
9 This comprises the countries of Lebanon, Palestine, Jordan and Syria.

${ }^{10}$ In addition to the exiting 1400 MW IC between Spain and Morocco the "Pessimistic" scenario also considers 1000 MW IC between Italy and Tunisia and as much additional interconnection between Algeria and Spain.

11 The reference (optimistic) scenario envisage the development of a reinforced Morocco-Spain IC with 2000 MW, Tunisia-Italy 1000 MW (2000 MW), Algeria-Spain 1000 MW (2000 MW), Algeria-Italy 1000 MW (2000 MW) and Libya-Italy 1000 MW (2000 MW). See L'Abbate et. al (2014) p. 370.

${ }^{12}$ It also might be the case that the interconnected electricity systems in the SEMCs have mostly similar demand and generation patterns and thus cannot be helpful for each other.
} 

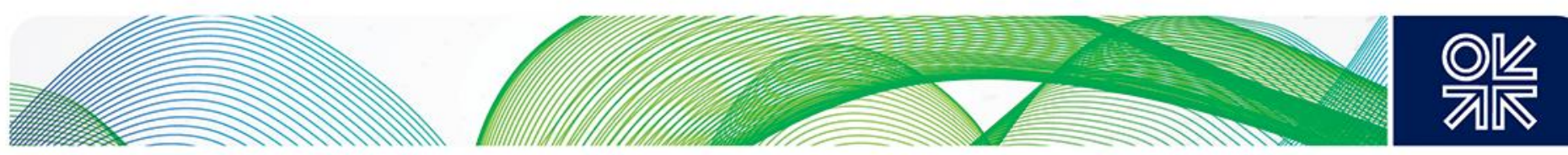

interconnections. This significantly reduces the strategic risk associated with previous projects, like Desertec, that involved only the imports of renewable energy into Europe from North Africa. The SpainMorroco interconnection is a potential benchmark for the development of another North-South cable between Italy and Tunisia. In the medium term, the IC would be used to export abundant Italian capacity, and improve the security and sustainability of electricity supply in Tunisia. In the long run, the IC could be used to export RES from the SEMCs to Europe, once the untapped potential becomes fully exploited.

Table 1: Interconnection exchange

\begin{tabular}{|c|c|c|c|}
\hline Interconnection & $\begin{array}{c}\text { Max transfer capacity } \\
\text { (MW) }\end{array}$ & $\begin{array}{c}\text { Energy exchanged } \\
\text { (GWh/Year) }\end{array}$ & $\begin{array}{c}\text { Load factor } \\
\text { (\%) }\end{array}$ \\
\hline Spain-Morocco & 700 & 4227 & 69.0 \\
\hline Morocco-Spain & 700 & 15 & 0.2 \\
\hline Morocco-Algeria & 400 & 613 & 17.0 \\
\hline Algeria-Morocco & 400 & 662 & 19.0 \\
\hline Algeria-Tunisia & 150 & 141 & 11.0 \\
\hline Tunisia-Algeria & 150 & 122 & 9.0 \\
\hline Libya-Egypt & 180 & 152 & 10 \\
\hline Egypt-Libya & 180 & 70 & 4 \\
\hline Egypt-Jordan & 450 & 363 & 1 \\
\hline Jordan-Egypt & 200 & 9 & 90 \\
\hline Egypt-Palestine & 17 & 134 & 90 \\
\hline Jordan-Palestine & 20 & 158 & 2 \\
\hline Jordan-Syria & 350 & 69 & 1 \\
\hline Syria-Jordan & 200 & 20 & 97 \\
\hline Turkey-Syria & 250 & & 9 \\
\hline
\end{tabular}

Source: Habib El Andaloussi (2010)

One of the reasons that previous projects such as Desertec (a plan to transfer solar power from North Africa to Europe) have stalled is that they were designed around a one-dimensional business model, i.e. the export of renewable from North Africa to Europe. This has two problems. First, demand for electricity in EU countries is already stagnant (due to continued recession, demographic changes, and improved energy efficiency among others), leaving it with idled excess capacity. Second, demand in many North African countries is increasing, casting doubt over whether or not these countries will have enough supply to be reliable exporters to the EU. In order for projects of these kinds to be viable, they need to be developed around market synergies, integrated markets and complementarity. 

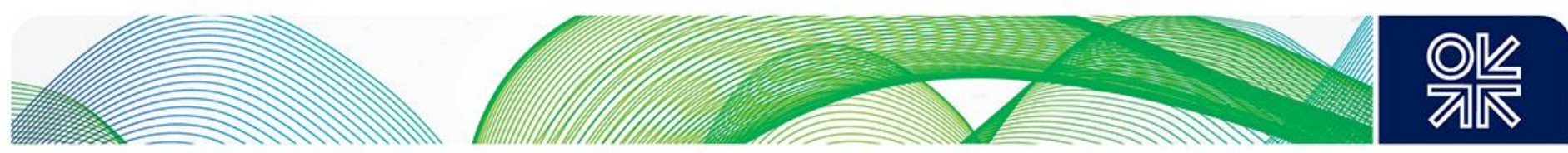

Therefore, given the strong complementarity of the basin's energy systems and the unexploited potentials for more integration and energy exchange, we argue that initially EU excess capacity and, in the long run, renewable energy affect interconnection investments in both shores of the Mediterranean region. According to the 2030 scenario depicted by the Energy Union, and underlined by Med-TSO Technical Committee, in the long run the significant development of RES will constitute the single main driver of pan-European transmission network expansion. Effective RES deployment means that electricity will be generated in the most efficient locations, often far away from consumption hubs (European Commission, 2010), requiring long distance interconnection with neighbouring countries. In order to achieve its ambitious targets, the EU placed a great emphasis on the development of transmission interconnections, defining a number of policy tools to enable the necessary investment in grid infrastructure. ENTSO-E (2014) estimates that $€ 150$ billion will be needed in order to reinforce the EU's electricity grid in the coming 15 years.

The EU's third energy package aims to unlock investment and facilitate the deployment of cross-border interconnections. In particular, to achieve the interconnection targets, dedicated policy tools are introduced to deal with the pitfalls that previous instruments failed to address (see section 4, and Rubino and Cuomo, 2015). While it is still too early to evaluate the impact of the enhanced permit granting procedures introduced with Projects of Common Interest (PCls), the evidence available so far highlights that Transmission System Operators (TSOs) in most EU countries do not have the right incentives to invest in cross-border interconnection (Brunekreeft, Newbery, \& Neuhoff, 2005; Littlechild, 2003) or lack the capital required to make such significant investments. This also holds true for most SEMCs, where the energy sector (and the electricity sector in particular) has traditionally suffered from insufficient investments. At time when several countries are progressively removing energy subsidies (El-Katiri and Fattouh, 2015), and when governments are looking for budget flexibility to push forward employment and social policies, finding additional regulated investment that will, at the end, be paid by the consumers, might prove difficult.

Therefore, whereas regulated cross-border interconnections are envisaged as the default option, private (non-regulated) actors might be needed to play a significant and probably more fundamental role, on both side of the Mediterranean basin. However, a review of the business model for existing cross-border interconnections in SEMCs shows that all are regulated lines (see Table A1 in the appendix). Moreover, the 16 currently planned ICs (refer to Table 2) are also foreseen as regulated lines. According to MedReg (2015) of the new proposed cross-border lines, only the Egypt-Saudi Arabia link is at an advanced state of planning. It reached the permitting phase and is scheduled to start construction in 2016. The remaining projects are at preliminary stages (feasibility or earlier stages) and have an uncertain degree of viability when project financing is taken into consideration.

According to the European Commission (EC), the Merchant Transmission Initiative (MTI) will contribute to providing enhanced regional integration. Some merchant lines are included as $\mathrm{PCl}^{13}-$ the list of investments which have a special priority - and believed to be able to significantly increase the current interconnection capacity. However, the different risk profile of $\mathrm{MTI}$, compared with regulated transmission lines, requires specific treatment and exemptions from parts of the regulatory framework (European Commission, 2015, pp. 10). The use of MTI in SEMCs can be even more challenging, despite the greater need for infrastructure enhancement and investments in these countries.

While the debate around the most appropriate regulatory and market model is in its infancy, and will be discussed in more detail below, some general results have already emerged. These results suggest that the design which allows for an optimal configuration of a regional network requires the definition of a standard reference model, or an even stronger institutional constraint, such as a regional framework

\footnotetext{
${ }^{13}$ Introduced with Regulation 347/2013.
} 

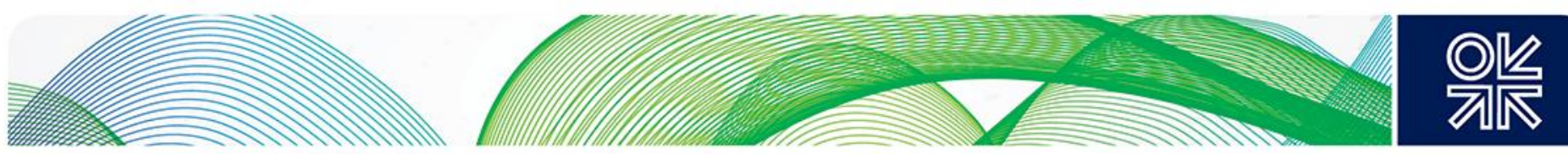

treaty, that enables interested parties to maximise the benefit of using an integrated approach ${ }^{14}$ (Woolley, 2013). This, of course, is contingent upon the existence of a stable political situation.

\begin{tabular}{|c|c|c|c|c|c|c|c|}
\hline $\begin{array}{l}\text { From } \\
\text { country }\end{array}$ & Year & Type & $\begin{array}{l}\text { Project } \\
\text { status }\end{array}$ & $\begin{array}{l}\text { To } \\
\text { country }\end{array}$ & $\begin{array}{l}\text { Voltage } \\
\text { level }\end{array}$ & $\begin{array}{l}\text { Line } \\
\text { capacity } \\
\text { (nominal) }\end{array}$ & $\begin{array}{l}\text { Financial } \\
\text { availability }\end{array}$ \\
\hline \multirow[t]{2}{*}{ Algeria } & -- & & -- & Morocco & $400 \mathrm{kV}$ & $1200 \mathrm{MW}$ & -- \\
\hline & -- & & -- & Tunisia & $400 \mathrm{kV}$ & $1200 \mathrm{MW}$ & -- \\
\hline \multirow[t]{4}{*}{ Egypt } & 2025 & New & $\begin{array}{l}\text { Feasibility } \\
\text { Phase }\end{array}$ & Sudan & $\begin{array}{l}600 \mathrm{kV} \\
\text { (DC) }\end{array}$ & $2000 \mathrm{MW}$ & No \\
\hline & 2016 & New & $\begin{array}{l}\text { Permitting } \\
\text { Phase }\end{array}$ & $\begin{array}{l}\text { Saudi } \\
\text { Arabia }\end{array}$ & $\begin{array}{l}500 \mathrm{kV} \\
\text { (DC) }\end{array}$ & $3000 \mathrm{MW}$ & Yes \\
\hline & $\begin{array}{l}\text { Deferred due to } \\
\text { political } \\
\text { situations }\end{array}$ & Upgrade & $\begin{array}{l}\text { Feasibility } \\
\text { Phase }\end{array}$ & Libya & $\begin{array}{l}500 / 400 \\
k V\end{array}$ & $500 \mathrm{MW}$ & No \\
\hline & & New & Feasibility & Palestine & $220 \mathrm{kV}$ & 150 MVA & Yes \\
\hline \multirow[t]{3}{*}{ Jordan } & -- & New & $\begin{array}{l}\text { Feasibility } \\
\text { Phase }\end{array}$ & Palestine & $400 \mathrm{kV}$ & 1000 MVA & No \\
\hline & & New & & $\begin{array}{l}\text { Saudi } \\
\text { Arabia }\end{array}$ & $400 \mathrm{kV}$ & $500 \mathrm{MVA}$ & \\
\hline & & Upgrade & & Egypt & $400 \mathrm{kV}$ & 1200 MVA & \\
\hline \multirow[t]{3}{*}{ Libya } & 2017 & New & $\begin{array}{l}\text { Feasibility } \\
\text { Phase }\end{array}$ & Egypt & $\begin{array}{l}400 \text { kV - } \\
\text { Libyan } \\
\text { side }\end{array}$ & $500 \mathrm{MW}$ & No \\
\hline & & & & & $\begin{array}{l}500 \text { kV - } \\
\text { Egyptian } \\
\text { side }\end{array}$ & & \\
\hline & & & & Tunisia & $400 \mathrm{kV}$ & $500 \mathrm{MW}$ & \\
\hline \multirow[t]{2}{*}{ Morocco } & -- & -- & -- & Algeria & $400 \mathrm{kV}$ & $1200 \mathrm{MW}$ & -- \\
\hline & -- & -- & -- & Spain & -- & 50MVA & -- \\
\hline \multirow[t]{2}{*}{ Palestine } & -- & New & $\begin{array}{l}\text { Feasibility } \\
\text { Phase }\end{array}$ & Jordan & $400 \mathrm{kV}$ & $150 \mathrm{MVA}$ & No \\
\hline & & & & Egypt & $220 \mathrm{kV}$ & & Yes \\
\hline Tunisia & -- & -- & -- & Libya & -- & $500 \mathrm{MW}$ & -- \\
\hline
\end{tabular}

Source: NRAs data, MedReg consultation (2015)

${ }^{14}$ Some studies suggest that the formation of a regional grid which ultimately results in a combination of different cross-border links is highly path dependent (see, Leveque et al., 2012).

Business model for cross-border interconnections in the Mediterranean basin 

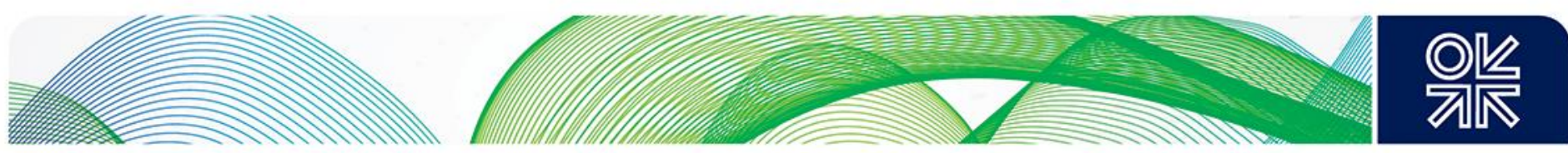

\section{The interconnection investment models}

There are two polar approaches for investment in interconnection capacity: regulated and merchant models. Regulated investment has been the traditional approach for transmission expansion. However, the merchant model's introduction sparked a debate as to whether it can be a substitute for regulated investment (see for example, Hogan, 1992; Bushnell and Stoft, 1996; Joskow and Tirole 2003; Brunekreeft, 2004; Brunekreeft et al., 2005; Brunekreeft, 2005; Littlechild, 2012). The endeavour even extended into alternative models based on the combination of the best elements in the merchant and regulated methods (see for example Hogan et al., 2010). This section briefly reviews the latest debate on the choice of interconnection business model along with the current exempted interconnectors in the EU and provides some insights into the conditions that lead to one model being favoured over the other.

\subsection{Regulated investment model}

Transmission systems are considered to be a natural monopoly and thus subject to economic regulation. The transmission system operator (TSO) is not only assigned with the task of operating and managing the existing network but also carrying out new investment, including on interconnections. The regulatory authority needs to verify the prudence of new investments in order to allow the TSO to go forward with the investment plan. The investment costs are then included in the TSO's regulatory asset base to be recovered through the regulated network tariff.

Therefore, in regulated interconnections, the investors' revenue does not depend on the amount of congestion in the interconnection but only on the flow of power. For congested interconnections, a nondiscriminatory efficient congestion management method (for example an auction) must be designed to allocate the interconnection capacity. Under EU regulations, the congestion rent ${ }^{15}$ obtained by the regulated transmission investor is not an extra source of revenue. Instead, it must be used to ensure the availability of allocated capacity, maintain the current network or carry out new investment in interconnection capacity and be distributed among the network users through rebated tariffs ${ }^{16}$ (Kapff and Pelkmans, 2010).

Traditionally, regulated investment in transmission capacity has been the method of choice in many countries, including in Europe. This is mainly because of its simplicity, the maturity of relevant institutions, the discretionary power of regulator over the details of business plan (where, when and how to build the interconnection) and last but not the least, the guaranteed return on investment. However, in practice, the regulated model has failed to deliver the necessary investment in interconnection capacity.

There are several reasons for the failure of the regulated model in promoting interconnection capacity (Kapff and Pelkmans, 2010). First and foremost, direct regulation which obliges TSOs to invest in interconnection capacity does not provide sufficient incentive, especially when unbundling is weak. The TSO has little incentive to invest in a new interconnection which leads to increased competitive pressure against its own generation facilities. Second, a new interconnection, following construction, is a sunk investment and thus investors require credible commitment from the regulator that it will adhere to the terms of the business plan agreed upon in the approval process (for example, a stable regulated tariff).

\footnotetext{
${ }^{15}$ Congestion rent is the price differential between two price zones times the volume of transported electricity. Congestion rent is an indication of insufficient interconnection capacity between zones. When there is sufficient capacity between two zones, the prices converge and thus rent disappears.

${ }^{16}$ In 2007 total congestion rent on interconnections reported to be around $€ 1.7$ billion by ESTO members out of which $83 \%$ is redistributed in the form of reduction in regulated tariffs (Kapff and Pelkmans, 2010).
}

Business model for cross-border interconnections in the Mediterranean basin 

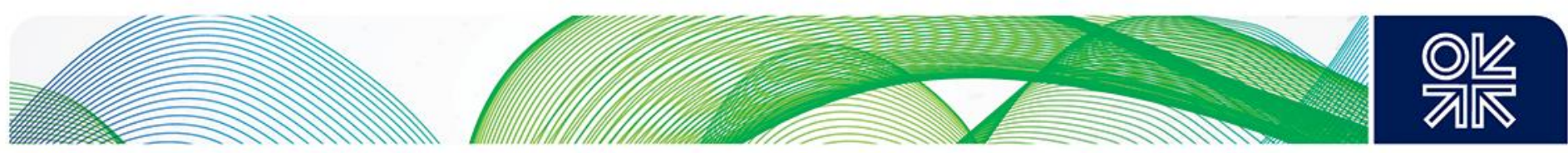

Regulatory uncertainties, such as regulatory opportunism or the threat of the regulator backing out of the agreement, can disincentivise investment. Third, the TSO may have a myopic attitude and fail to see the need and opportunity for investment despite the genuine economic case for a new interconnection. Finally, financing of new interconnection lines through uplift in regulated tariffs may face political resistance.

\subsection{The merchant model}

Merchant transmission initiative (MTI) is a profit-motivated investment in cross-border interconnection which is exempted from regulation (de Hauteclocque and Rious, 2011). Under MTI, investment costs can be recovered either through the congestion rents or the sale of financial (or physical) transmission rights (FTRs). FTRs, which are usually allocated in a market-based fashion (for example auction), entitle the holder to the price difference between two nodes. In other words, rather than receiving the price difference at both ends of interconnection, the merchant investor sells the FTR and allows the purchaser to hedge against locational price differences. In a similar manner, physical transmission rights provide the holder with access to the physical interconnection capacity.

Although the regulated model is currently the main approach for investment in interconnection, its performance with respect to investment incentive has proved unsatisfactory. The dissatisfaction with the regulated model caused some regulators around the world to allow for merchant transmission initiative with the hope it would spur new investment. Under a set of assumptions ${ }^{17}$, the merchant model appears to solve the problem of incentive, which is a serious impediment under the regulated investment model. The expectation is, given the assumptions of the merchant transmission initiative model, an efficient investment is profitable and an inefficient investment is unprofitable.

Despite the appealing theoretical properties of the merchant model, the underlying assumptions have been subject to criticisms in various studies, including Joskow and Tirole (2003), for being unrealistic. According to them, the issues such as market power with transmission investment, imperfect information, transaction costs, lumpiness of investment, long lead times and lack of a forward market and commitment seriously undermine the attractiveness of the merchant transmission initiative. Therefore, contrary to what theory predicts, in practice the merchant model leads to lower than socially optimal investment levels, strategic profit maximising operation and delayed investment which deters real market integration in the long run (Joskow and Tirole, 2003).

However, through examining the cases of merchant interconnectors in Australia and Argentina, Littlechild (2012) shows that those conjectured theoretical limitations have not been serious problems in practice. Moreover, he argues that many of the aforementioned features that are considered to be problematic for MTI can also be problematic for regulated investment. Contrary to Joskow (2005), which claims that MTI might be a compliment but not a substitute for regulated transmission investment, Littlechild asserts that it is the matter of choosing between two imperfect alternatives. In this view, neither of these models have an inherent absolute advantage over the other. Rather, it is the contextual conditions of each specific project that dictate which model fits best. Table 3 summarises the key characteristics of regulated and merchant investment.

\footnotetext{
${ }^{17}$ These assumptions are: no sunk cost and asset specificity, no increasing return to scale, efficient wholesale market, nonstochastic transmission capacity which is unaffected by TSO or ISO decision, presence of future markets and finally nodal prices which reflect all externalities as well as consumer willingness to pay (Joskow and Tirole, 2003).
} 

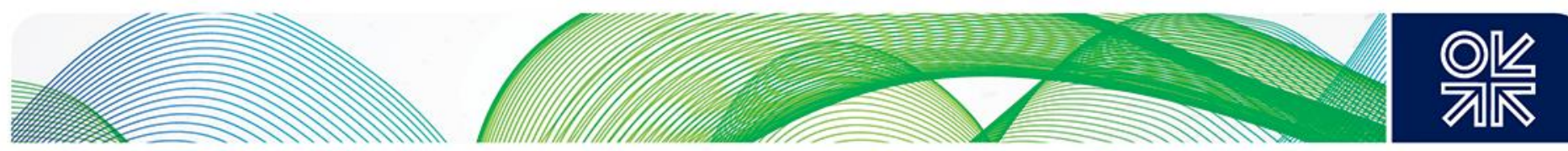

Table 3: Key characteristics under regulated versus merchant interconnector Regulated model Merchant model

\begin{tabular}{|c|c|c|}
\hline Investor & Often TSOs or regulated utilities & Private investor \\
\hline Main objective & Improving reliability & Making profit \\
\hline Payer & Captive consumers of utility company & $\begin{array}{l}\text { Market players who buy } \\
\text { transmission rights }\end{array}$ \\
\hline Business model & $\begin{array}{l}\text { Return on regulatory asset base } \\
\text { under incentive regulation }\end{array}$ & $\begin{array}{l}\text { Value of congestion rents and } \\
\text { other potential revenues }\end{array}$ \\
\hline Tariff setting & Regulated tariff approved by authority & $\begin{array}{l}\text { Exempted from regulated tariff } \\
\text { setting }\end{array}$ \\
\hline Risk & Risks are mainly borne by rate payers & $\begin{array}{l}\text { Risks are mainly transferred to } \\
\text { investors }\end{array}$ \\
\hline $\begin{array}{l}\text { Regulator's main } \\
\text { concern }\end{array}$ & Lack of incentive for investment & Allocative inefficiency \\
\hline
\end{tabular}

Source: authors own compilation and Frayer (2013)

Therefore, the evidence for whether the merchant model is a substitute or a compliment for regulated investment remains inconclusive. Along with research on the weakness and strength of each method, some studies explored the possibility of reconciling regulated and merchant models. A notable example is Hogan et al. (2010) which proposed an innovative approach to combine the best practices of the two approaches for a TSO (the owner of the grid) operating under an ISO institutional setting where the ISO defines the reliability constraints and TSO undertake the necessary investment given the technical properties of the network. In their model, a price cap method is suggested to regulate TSO where the output of the network is defined in terms of long-term financial transmission rights (LTFTRs). Defining outputs in terms of financial transmission rights (FTRs) connects the regulatory model to the merchant investment theory. The price cap regulation in their model includes a fixed and a variable cost. The variable cost will be recovered through the auctioning of the FTRs to the interested parties. The fixed fee, which would be paid by the load, as the user of the network, is determined by considering the price of the FTR in such a way that the average of fixed and variable costs does not exceed a predetermined level.

The investor can also be a merchant. The merchant is entitled to revenue from the FTRs on the additional point-to-point transmission made possible through its investment. In other words, in the end the merchant investor receives the congestion charges (reflected in the price of the FTR) plus or minus the fixed charges caused by the merchant investment (plus when the price of the FTR is lower than the pre-specified level and minus when it is higher). They argue that their model can address some of the main criticisms of the merchant approach such as lumpiness of investment and it does better than basic linear nodal pricing.

\subsection{Treatment of MTI under EU regulation}

The EU regulation strongly favours regulated interconnection as opposed to merchant model. Directive 2009/72/EC clearly states that TSOs are responsible for developing transmission infrastructure including interconnections to ensure long-term reliability of the power system (OJ, 2009). In this framework, the merchant investment is seen as an exception, in the sense that it is only considered when the risk of project is such that that investment will not take place unless the exemption is granted. Any eligible project can be exempted from some or all of regulatory restrictions. Figure 4 presents the four categories of regulatory restrictions (regulated third party access, use of congestion charges, unbundling and charging method) which an interconnector can be exempted from fully or partially. 

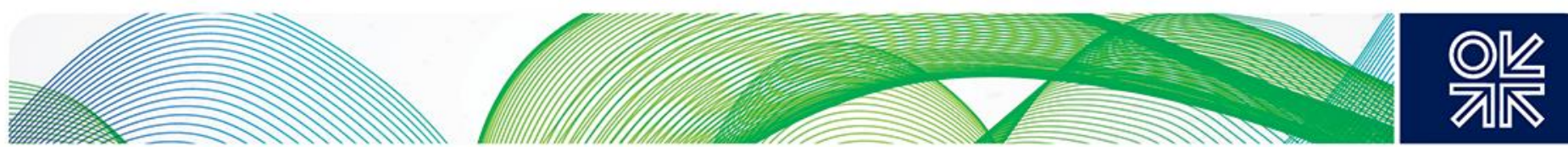

Figure 4: The four areas of exemption

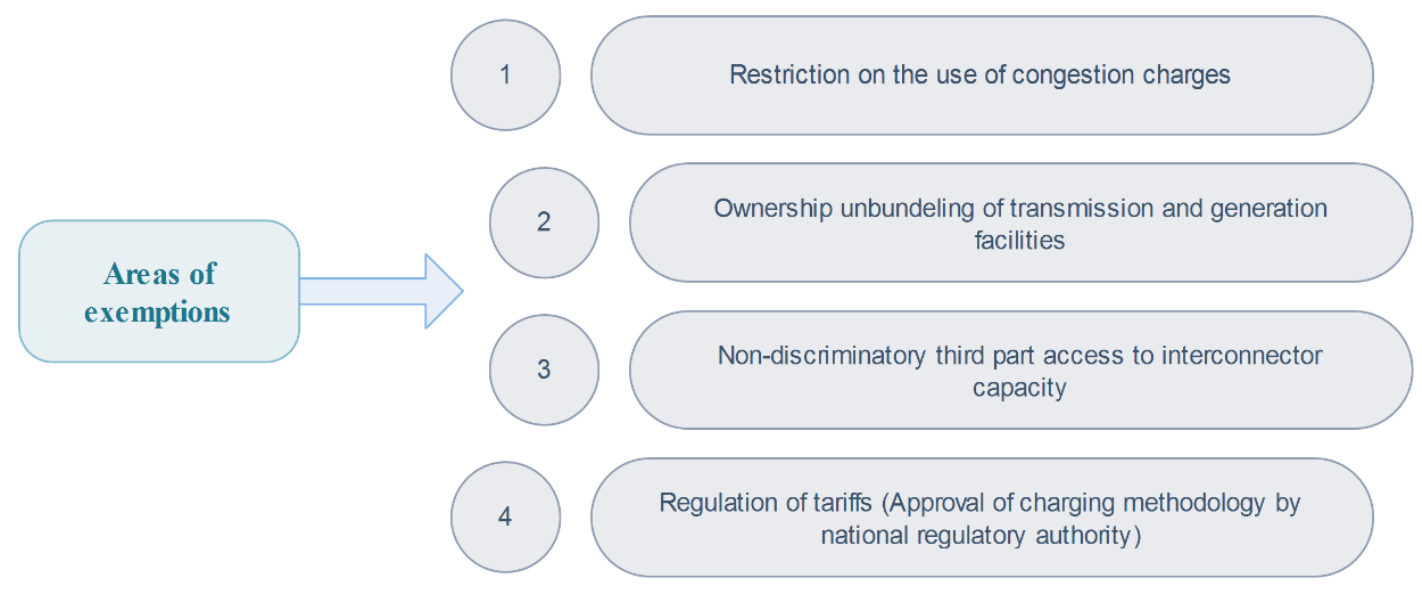

Source: Authors

The criteria for granting exemption is set out in article 17(1) of regulation (EC) No 714/2009 of the European parliament (EU, 2009). These requirements include six conditions as presented in Figure 5. For an exemption to be granted, the interconnector must meet all the six conditions stated in the regulation. The burden of proof for satisfying these conditions is on the shoulders of the merchant investor. The case for exemption needs to be initially approved by the national regulatory authority (NRA) (based on the specific circumstances of the project) before being sent to the European Commission (EC) for final decision. The EC reserves the right to accept unconditionally, overturn the NRA decision or approve subject to further conditions when a project does not strictly meet one or more of the requirements for exemption. The fact that the EC decision is not binary (accept or reject) indicates that the project's specific features matter a great deal.

Figure 5: Conditions for exemption

\begin{tabular}{|c|c|}
\hline \multirow{6}{*}{$\begin{array}{l}\text { Conditions for } \\
\text { exemption }\end{array}$} & 1- Investment must enhance competition in electricity supply. \\
\hline & $\begin{array}{l}\text { 2-Risk of project is so high that investment would not take place without exemption being } \\
\text { granted. }\end{array}$ \\
\hline & $\begin{array}{l}\text { 3-Interconnector must be owned by a natural or legal entity and is legally separate from the } \\
\text { system operator of the region. }\end{array}$ \\
\hline & 4-Charges are levied on the users of interconnector. \\
\hline & $\begin{array}{l}\text { 5-No parts of capital or operational expenditures have been claimed from any components } \\
\text { of charges for transmission or distribution network to which interconnection is connected. }\end{array}$ \\
\hline & $\begin{array}{l}\text { 6- Exemption must not comes at the cost of ineffective operation of internal electricity market } \\
\text { or inefficient functioning of regulated system governing interconnector. }\end{array}$ \\
\hline
\end{tabular}

Source: Authors

Up to now, the EC has granted five exemptions for merchant interconnectors, and in most cases imposed additional conditions to ensure regulatory compliance (Rubino and Cuomo, 2015). Figure 6 presents a summary of these projects including their specifications, exempted restrictions and conditions imposed by the EC. Examining these exempted cases reveals that not all of them can be

Business model for cross-border interconnections in the Mediterranean basin 

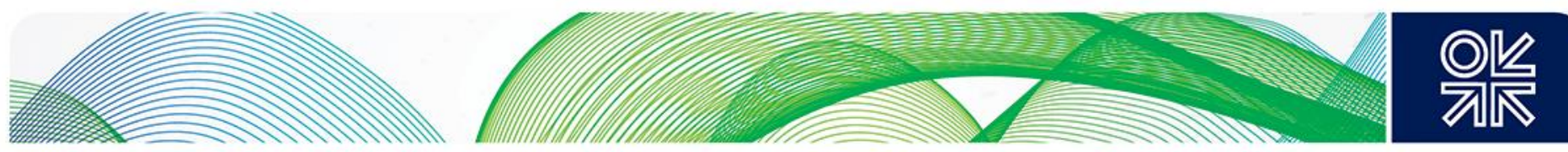

considered as a merchant project in the way that it is discussed in the literature. This is because, for instance, the investors are the current market players rather than new entrants. Additionally, under EU laws an interconnector can be exempted from the restrictions on the use of congestion revenues but still required to adhere to the third party access regulation (for example, Travisio-Arnoldstein interconnector between Austria and Italy). Nonetheless, in at least two cases investors are non-market players who are exempted from most regulatory restrictions and thus more similar to the theoretical merchant model (for example, ElectLink interconnector between GB and France).

A salient feature of regulatory exemptions under EU laws is its degree of reliance on independent evaluations in order to verify information provided by the merchant. From the regulator's perspective, a concern is that the investor might overestimate the risk facing the project and thus a less risky project is rewarded more than its full economic costs. This concern has already been seen in the case of the East-West cable where despite the fact that exemption was granted, EC rejected Imera's claimed level of risk on the ground that it was exaggerated. The asymmetric information between the investor and regulatory authorities is thus an issue under the EU treatment of merchant interconnector. This is important as some investors are genuinely exposed to financial and/or operational risks and regulators need to distinguish them from the cases where investors are trying to game the regulator. For example, non-TSO investors are more constrained compared with TSOs and thus are exposed to higher risks due to their inability to recover losses from the national transmission grid revenues (Rubin and Cumo, 2015). Therefore, non-TSO investors have more incentives to apply for exemption.

\section{Figure 6: The exempted interconnectors in EU}

A $105 \mathrm{Km}, 350 \mathrm{MW}$ submarine HVDC cable between Finland and Estonia. Fully exempted from regulatory third party
access and the restrictions on the use of congestion charges which expired on 31 December 2013 and the ownership
transferred to Finish and Baltic TSOs. Capacity was fully reserved for Baltic generators. One way power transfer from
Baltic to Finland. Capacity charges are imposed irrespective of the use. No condition imposed by EC.

A $260 \mathrm{Km}, 1000 \mathrm{MW}$ submarine HVDC cable between Britain and Netherlands. Owned equally by National Grid and
Dutch transmission grid (Tennet). 25 years exemption from regulated access charges and the use of congestion revenues.
The costs are recovered through the sale of capacity in various explicit and implicit auctions in the medium, daily and intra-
day terms. Short term contracts are used exclusively. EC imposed the condition of ten years follow up review.
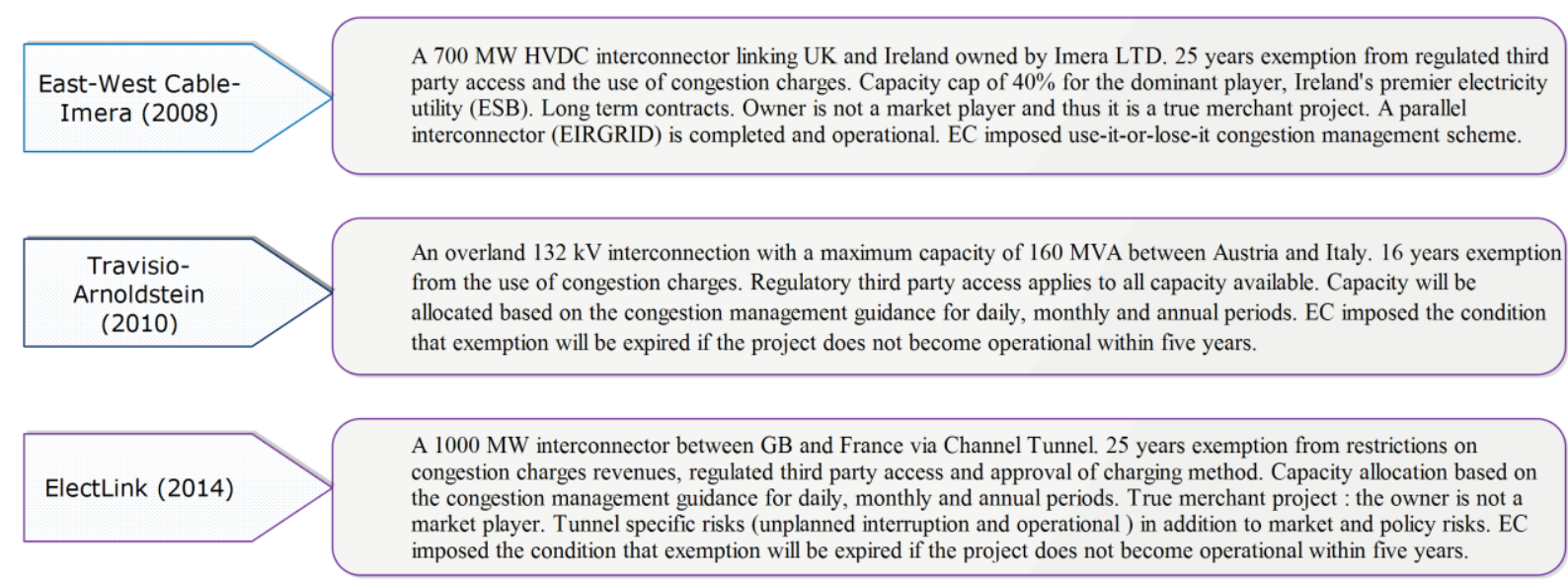

Source: Authors based on information in Rubino and Cuomo (2015)

Although the EU regulation has been clear in terms of providing guidance on promoting interconnections, the effectiveness of the EU model to incentivise the cross-border interconnection in 

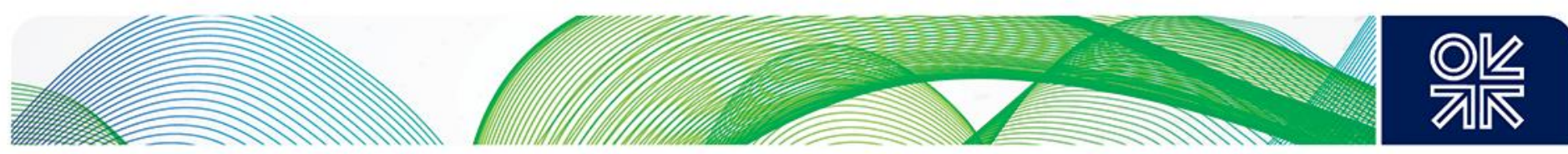

the Mediterranean region is subject to debate. We contend that the EU model only partially responds to the different energy needs of the region for two main reasons:

- Firstly, energy interconnection regulation (and electricity interconnection in particular) in the EU has been developed in response to the specific situation and the need to implement crossborder interconnection to enhance regional competition among MS incumbents and dominant players. However, we argue that security, continuity and quality of energy supply are the main drivers of cross-border interconnection development in the MENA region;

- Secondly, matters related to cross-border interconnections in the EU are referred to in the Regulation (EC) No 714/2009 and Directive No 2009/72/EC. Those provisions promote electricity interconnector investment within a regulated access regime, an arrangement which may not be sufficient to deliver interconnection in the Mediterranean region. The Directive states that each transmission system operator (TSO) is responsible for developing infrastructure as a means of "ensuring the long-term ability of the system to meet reasonable demands for the transmission of electricity". The Commission assumes that the applicable national regulatory authority (NRA) provides "tariff incentives and appropriate economic signals to encourage" TSOs to invest in new infrastructure such as a cross-border electricity interconnector. In this framework, and exceptionally, in order to facilitate the development of interconnectors on a voluntary basis the regulation allows exemption from the regulated access regime when a project's risk level is judged to be prohibitive to investment.

However, the current situation in most SEMCs is radically different from that of the EU at the time when the third package was adopted. In particular, investors typically take into account a number of aspects (which are considered crucial when deciding whether to undertake an investment in emerging economies) that will have an exceptionally high impact on the perceived level of risk for infrastructure in most SEMCs. In particular, matters related to the regulatory certainty, the stability of the legal and regulatory framework, market reform and political stability are determinant in defining the financial feasibility of each investment project. This will in turn make the regulated investment highly unlikely or only possible at prohibitively high rate of returns.

Therefore, given the extremely tight public budget constraint currently experienced in most Mediterranean countries and the high level of perceived risk for cross-border investments along with the considerable liquidity in financial markets and the existing generation overcapacity in Europe, an alternative business model for interconnection in the Mediterranean basin needs to be defined and proposed. In this perspective the European experience can be considered as a useful starting point for the definition of a "Mediterranean approach" to infrastructure development that shall consider an enhanced role for public-private partnerships.

\section{Regulatory framework for a viable interconnection business model}

The current EU interconnection capacity with Non-EU countries is limited. Insufficient experience combined with significant disparities between the EU and Non-EU countries in terms of stage of development, market maturity, institutions and regulations and political stability are the main barriers for further development of interconnections. The EU regulation needs to overcome the barriers of socially beneficial investments and promote efficiency. For this to happen, there needs to be a viable business model. The key features of a viable business model are: a) incentives for investment and efficient operation b) management of risk and uncertainties c) coordinated planning and governance (see Figure 7). These features are influenced by a myriad of factors pertaining to the operating

Business model for cross-border interconnections in the Mediterranean basin 

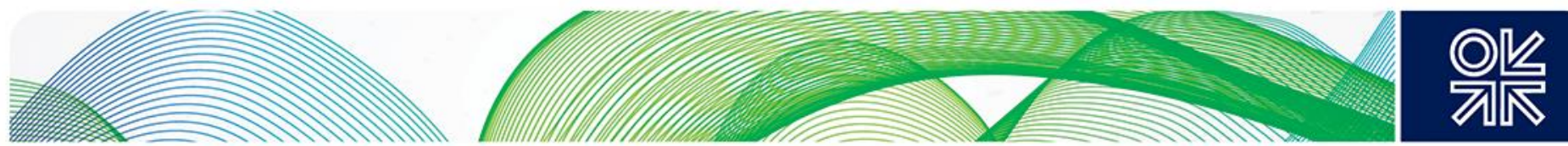

environment for interconnections, regulations, institutions and government objectives. In what follows, the key features of the viable business model for interconnection development are discussed in the context of the EU regulatory framework for grid expansion.

Figure 7: The main elements of a viable business model for interconnection investment

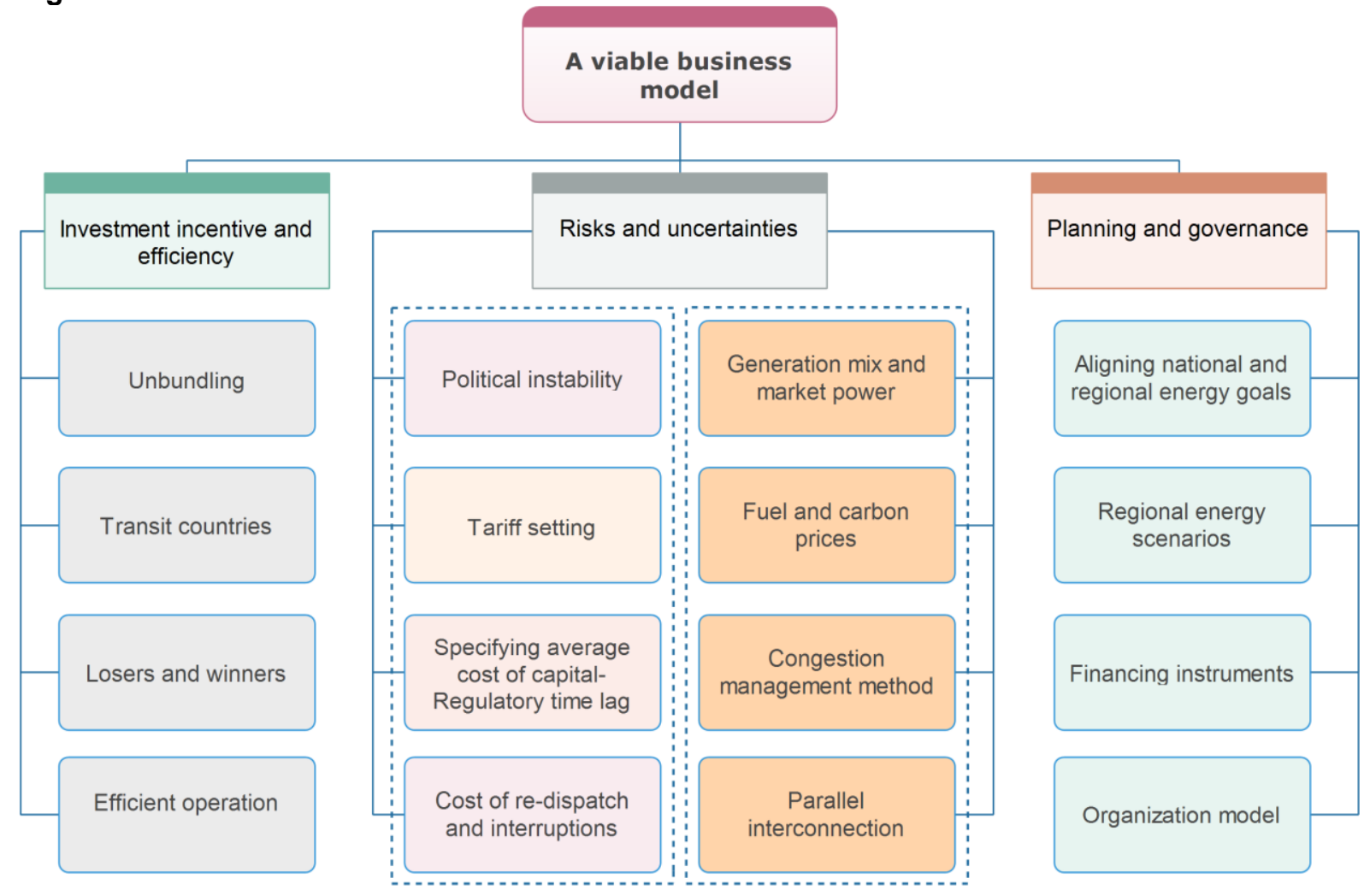

Source: Authors

\subsection{Investment incentive and efficient operation}

There are at least six incentive issues applicable to the investment in interconnections in the Mediterranean region. First, the power sector in many of the non-EU countries of the Mediterranean region has not been liberalised yet. So there is little incentive for a vertically integrated utility to invest in interconnections and promote competition against its own generation assets, unless demand grows at a faster pace than what a single vertically integrated utility is able to supply ${ }^{18}$. Even among the EU countries, weak unbundling in some places has adversely affected the incentives for TSOs to invest. Second, when multiple countries become interconnected, the transit countries may be resistive toward interconnectors simply because they do not benefit from the project proportional to the cost of infrastructure going through their region. Third, an interconnection which is socially beneficial may create winners and losers because of wealth transfers between consumers and utilities as a result of price changes in two connected nodes. Therefore, the regulatory authorities in the low pricing node might be reluctant to authorise such investment if it leads to price increase in their area. Fourth, although

\footnotetext{
${ }^{18}$ The inability to match fast growing demand can create pressure for capacity expansion. IC can provide some additional capacity without introducing competition in the market.
}

Business model for cross-border interconnections in the Mediterranean basin 

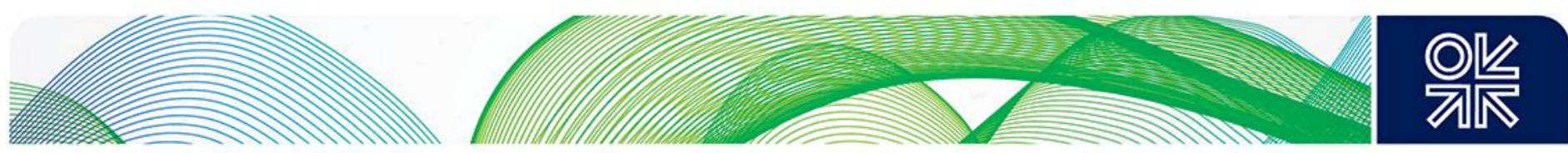

private investors can enter where the incumbent TSOs lack the incentive and capacity to invest in the interconnection, cost recovery through price differences implies that a socially efficient interconnection capacity will not be profitable (i.e., a social efficient capacity will lead to price convergence between two nodes and thus zero congestion rent). Fifth, due to the uncertainty in price differences, a pure merchant model can lead to a situation that only profitable investments go forward and non-profitable yet socially beneficial investments are left for regulated TSOs (Neuhoff et al., 2012). Sixth, the merchant model may lead to strategic withholding of capacity and inefficient operation.

These incentive issues are barriers for a viable business model; they require an effective regulatory framework to overcome obstacles. This extends from removing barriers to private investment and promoting unbundling to developing efficient cost allocation systems and effective capacity management. Table 4 provides a summary of the incentive issues along with possible approaches to resolve them.

\begin{tabular}{l} 
Table 4: incentive issues and possible solutions \\
\begin{tabular}{|l|l|}
\hline Incentive issue & Possible solutions \\
\hline Vertically integrated monopoly & $\begin{array}{l}\text { Facilitating private investors entry. More } \\
\text { stringent unbundling regulations }\end{array}$ \\
\hline Transit country & $\begin{array}{l}\text { Efficient cost allocation system } \\
\text { Compensation of losers where feasible or } \\
\text { evaluating the project based on Kaldor-Hicks } \\
\text { efficiency criterion }\end{array}$ \\
\hline Winners and losers & $\begin{array}{l}\text { Partial decoupling of revenue from price } \\
\text { differences-Hybrid models }\end{array}$ \\
\hline $\begin{array}{l}\text { Non-profitable socially beneficial } \\
\text { investments }\end{array}$ & Modification of tariffs to strengthen incentives \\
\hline Capacity withholding & $\begin{array}{l}\text { Efficient capacity allocation (must offer- use it or } \\
\text { lose it arrangement) }\end{array}$ \\
\hline
\end{tabular} \\
\hline
\end{tabular}

Source: Authors

\subsection{Risks and uncertainties}

Investors in interconnectors are exposed to various risks and this affects their cost recovery, credit rating, cost of capital and profitability. These risks can arise from a variety of sources including: a) project-specific risks such as those related to construction, operation, dilution of demand for capacity and political instability b) market risks such as convergence of prices and erosion of congestion rents c) regulatory risk such as changes in congestion management guidance or revision of tariffs. Rating agencies often assess interconnectors' risk against a set of factors such as stability of the business model and regulatory uncertainty. As the risk and uncertainty are detrimental for investment, a key criterion for exemption granting to interconnectors under EU regulation is the degree of project riskiness.

A merchant business model faces various risks. The factors that affect the price of electricity at two connected nodes constitute important sources of risk. In liberalised electricity markets, generation investment decisions are independent of network operation. Such investments can change the generation mix at interconnected nodes with implications for price differences. Furthermore, the generator may have market power and this leads to distorted prices and consequently affects the cost recovery of merchant investment. Add to this volatile fuel and carbon prices, and it is clear that there can be significant uncertainties in congestion revenues. Besides, merchant investors face additional risks related to the change of guidance on congestion management method, construction of a parallel interconnection and the risk that the interconnection becomes a stranded asset. 

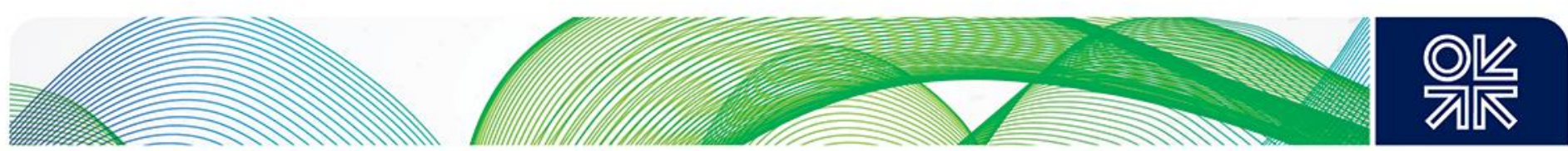

The issue of risk is not confined to the merchant model; a regulated business model also faces risks. These include uncertainty in tariff setting methodology, defining regulatory asset base, specifying an average cost of capital and time lag between cost incurrence and remuneration of capital costs.

In addition, there are risks applicable both to regulated and merchant models such as political instability, cost of re-dispatch due to interconnection internal constraints, power cut liabilities and diverse ownership and its effect on credit rating. The risks due to political instability are those pertaining to civil war, civil unrest, sabotage, expropriation, confiscations or nationalisation of assets, import/export embargo or border closure and breach of underlying contract among others. Although some of the political risks can be insured against, their cause is often beyond the control of the trading partners.

The regulatory framework of the business model can mitigate or aggravate investors' exposure to uncertainties. For example, by definition, a regulated interconnector is more protected against financial loss compared to a merchant model. If the risk of the project were beyond a certain level, a regulated return would not be sufficient to cover the cost of capital. Under this situation, seeking exemptions from regulated third party access and restrictions on the use of congestion revenues would be the natural approach for investors. Nonetheless, exemption from regulatory restrictions could impede cost recovery in the case of financial loss. Therefore, an investor faces a trade-off between lower risk and consequently a lower return regulated model on the one hand and a higher risk and potentially higher return merchant model, on the other hand.

A hybrid approach where effective elements of regulated and merchant models are combined can be a compromise to the problem of risk. Hogan et al. (2010) model manages the risk to investors and consumers by introducing a price cap regime with fixed and variable components where the variable part is recovered through the sale of transmission rights. In a similar manner, Ofgem (the British electricity and gas market regulator) has proposed a hybrid approach for investment in interconnections. The suggested method applies a cap and floor on the revenue obtained from the auctioning of interconnection capacity. The cap and floor level will be fixed for a long period (approximately 20 to 25 years) to provide investors with certainty. All revenues exceeding cap will be returned to the system operator and will be used to reduce network charges. In the event that revenues fall short of floor, interconnection users will pay the difference.

\subsection{Planning and governance}

Traditionally, transmission investment has been a national or a sub-national undertaking. Interconnections in the Mediterranean, by contrast, require regional and European level coordination. The presence of a supra-national regulator is important, as national regulators have no power on the other side of the border. Additionally, a European level strategy is needed to facilitate the interconnection of EU and non-EU countries. The infrastructure package provides a framework for the EU grid expansion to encourage coordination between the authorities at national, regional and EU levels. According to this package, a group of national regulatory authorities or private investors can propose a project with international relevance. Such projects are usually referred to as projects of common interest $(\mathrm{PCl})$. The main objective is to shorten the national and European permit granting process, removing regulatory barriers, and providing direct financial support for the $\mathrm{PCls}$ when financing through other channels is not available (Neuhoff et al., 2012).

Nonetheless, the current organisational structure for promoting these projects has not yielded the desirable results. For instance, the implementation of Trans-European Network for Energy (TEN-E) has been insufficient given the high volume of schemes which are classified under projects of European interest, priority projects and projects of common interest (von Hirschhausen, 2011). Thus, for a successful implementation, the number of projects in each of the aforementioned categories needs to be reduced to just a few important cases. Furthermore, a new organisational model is necessary in 

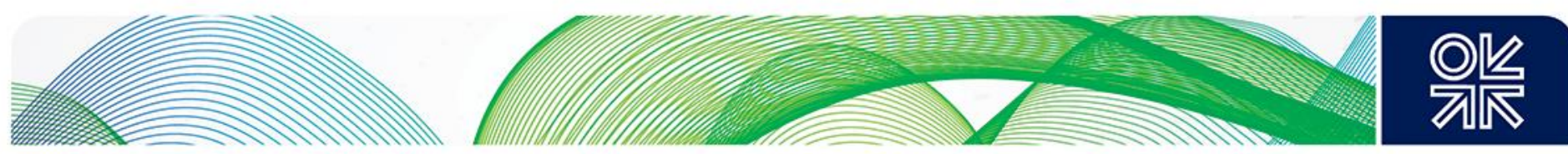

which European and non-European planning are aligned and new financing instrument are introduced to promote projects of common interest. This is specifically important as many of the TSOs cannot finance the required level of investment through raising debt, as increasing debt beyond certain limits downgrades the credit rating of these companies and this in turn increases the cost of capital (Neuhoff et al., 2012). On the other hand, new equity issuances can face political resistance in places with publicly-owned TSOs because it implies a reduction of government share.

\subsection{A Mediterranean interconnection model}

Although there are several aspects that appear to justify regional electricity trade and cross-border integration in the region, they are likely to impose a number of restrictions to the viable model. We identify below the main characteristics of the region's electricity system that provide the foundation on which the Mediterranean business model for interconnection and associated features needs to be designed.

Firstly, electricity systems of the countries in the basin show strong complementarity in the NEMCs and the SEMCs. The main driver for electricity exchange in EU-MENA is the exceptional demand growth in the south, caused mostly by demographic and macroeconomic reasons (see section 2). By linking countries and regions, interconnections allow the optimisation of electricity supplies, which can improve efficiency and may reduce the need for domestic investment in high-cost generation capacity and backup. In addition, stagnating demand in Europe is creating significant excess capacity in many NMCs. This leads to a situation that, unlike some projections depicting a south to north flow (Die, 2012; Khalfallah, 2015), foresees under almost all conditions ${ }^{19}$ the EU countries being the net exporters in the basin to satisfy growing demand in Egypt, Algeria, Tunisia and Morocco (L'Abbate et al., 2014). This flow might eventually revert after 2050 under the assumption that the RES potential in the south is fully exploited. The expected direction of electricity flow has consequences for the definition of the IC's business model because it affects the distribution of the price and volume risk between the parties involved.

Secondly, the generation mix currently shows a great dependency on gas and fossil fuels in the SEMCs, whereas Europe has developed a mixed portfolio of different sources. This difference is likely to underpin the opportunities for mutual gains in the short and medium run. In particular, interconnection (and the ability to acquire power through trade) might allow individual countries to have lower reserve requirements, which reduces the need (and the cost) for investment in reserve capacity.

Finally, renewed attention for the need for greater diversification of energy sources after the 2006 and 2009 Russia-Ukraine gas disputes has led to greater pressure to secure electricity cooperation with the south (Vantaggiato, 2016). Although the EU has emphasised the development of the internal energy market (IEM), Cambini and Rubino (2016) have demonstrated that market integration is perceived as a more significant driver than rules harmonisation. In practice, this means better adaptation of the prevailing liberalised model developed in the EU with the existing neo-realist approach ${ }^{20}$ (Escribano, 2010) widespread in North Africa. Typically, in these systems, "national champions", traditionally supported by governments, dominate the domestic markets, in which there is only a narrow, or no role, for competition. In the electricity sector and in the Mediterranean region these two paradigms coexist.

\footnotetext{
${ }^{19}$ The work developed by L'Abbate and colleagues (2014) depicted 5 different scenarios, all reporting export of excess electricity generation from the north to the south, via Mediterranean interconnectors, up to 2030.

${ }^{20}$ According to this approach, the relationships between consumers and producers are defined through bilateral long-term contracts, and national systems are interconnected only with point-to-point connections, most of the times only for mere network security reasons.
}

Business model for cross-border interconnections in the Mediterranean basin 

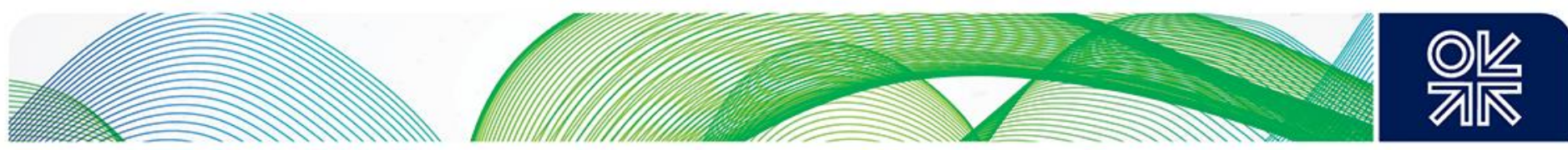

Therefore, taking into account the features of regional electricity systems mentioned above, along with the regulatory framework presented in the previous subsections, we propose a viable Mediterranean model for cross-border interconnection that package mutually reinforcing near-term outcomes with longterm objectives. When proposing a business model, policy makers often face a trade off between achieving a cost effective quantifiable impact that is typically associated with minimal regulatory changes, with a long term paradigmatic modification of the system dynamics. Our hybrid model is able to accommodate these two instances based on the following characteristics:

- Will initially be developed to export excess electricity capacity from Europe to North Africa,

- It is not based on RES trade, but is compatible with any development of the electricity mix. Therefore, it doesn't depend on the implementation of additional regulatory provision regarding the interpretation of article 9 of the directive 2009/28/EC.

- Will only address issues related to security of electricity supply and doesn't require or impose any structural change in the regulations of the domestic markets.

We now finalise our analysis by looking at the governance of the IC and its risk profile. Following Khalfallah (2015) we identify three interconnector options that are possible in the EU - North Africa interface: a point-to-point IC, a line transit IC and a network transit interconnection. Considering the characteristics described above, the Mediterranean model we are proposing will only take into consideration back-to-back lines that directly connects the EU exporting country with North Africa. In the absence of fast and significant developments in the definition of the regulatory and market conditions ${ }^{21}$ in the region, as per Med-TSO $(2015)^{22}$, we only consider the development of the minimal and common set of rules for construction and operation of the interconnection. These minimal rules are consistent with the definition of the Business as Usual (BAU) scenario and aligned with the development of the Mediterranean interconnections in 2030 in accordance with Ten Year Development Plan (TYNDP) 2016 of Med-TSO (see Figure 8). This is a conservative approach, aiming at minimising policy interventions and regulatory reforms. Following this approach, we rule out more onerous and ambitious configurations that foresee multinational interconnections and greater harmonisation of market rules. This implies that the only new North-South cross-border IC developed by then will connect Italy to Tunisia.

A point-to-point cross-border line could be organised as a regulated or as a merchant line, as described in section 4. However, as we have seen previously these two polar approaches give rise to new challenges. We, therefore, advocate a hybrid approach that could better fit the governance and risk structure emerging in the region. In this hybrid model, the ownership will be given to the exporting TSO, in order to guarantee the proper integration within the existing domestic network.

The proposed hybrid model is an alternative regulated investment scheme which intends to combine the contained risk of a regulated project with the less restrictive regulation of revenues of a merchant project. Contrary to the traditional regulated model where revenues and losses are predetermined by the NRA, in our model the NRAs determine a range for rate of return within which the implicit long-term contract between the generators and the importing TSO can be carried out. The application of a cap and floor model for interconnection is not new as, for example, the UK uses a similar approach to regulate interconnectors. However, our proposed model differs from the UK model in various aspects such as the ownership of asset, distribution of risks and trade direction among others. In this sense it is more a "flexible regulated model" rather than a merchant model.

\footnotetext{
${ }^{21}$ The $1^{\text {st }}$ Med-TSO assessment define moderately or poorly harmonised aspects such as: methods of capacity allocation, nomination of exchanges in the interconnections, publication of data-information and transparency, market and legal aspects. 22 "Assessment of regional cross border exchanges potential development in Mediterranean Region", MedTSO report available at http://www.med-tso.com
}

Business model for cross-border interconnections in the Mediterranean basin 

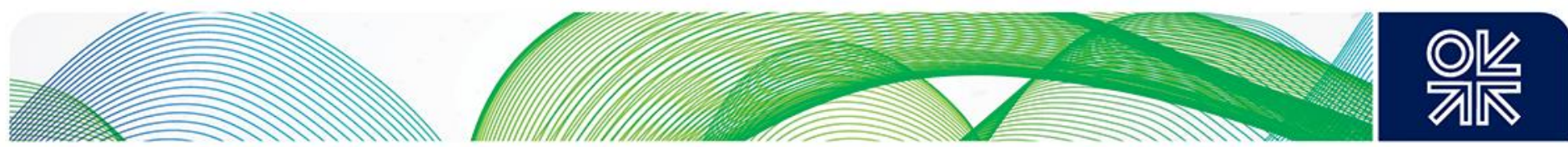

Since the IC is projected to inject the excess capacity available in the EU into the importing network, this investment needs to be underwritten by a long-term supply contract, subject to periodic revisions, that will also include some form of take or pay clause ${ }^{23}$. This is to share the risks between the counterparts in an efficient manner. In this construct, the buyer will take the volume risk, and the seller bears the price risk. In this way, consumers are protected from the cost implications of excessive returns or market power that might accrue to interconnector owners; developers are able to earn returns that are commensurate with the levels of risk to which they are exposed under the regulatory framework; and the regulatory treatment of developers are coordinated between the TSOs at either end of the shared asset, and approved by the NRA in Europe.

The cap and floor in the hybrid model is defined by the regulator of the exporting country ex-ante, and approved by MedReg ${ }^{24}$. The IC capacity allocation will be fixed for a long period of time but indexed to a measure of the cost of the marginal plant providing the generation exported (using a cost-based approach). In this scheme, losses to investors, when return falls below the floor determined by the NRAs, could be remunerated by an increase in the transmission tariffs paid by customers. A floor mitigates the risk due to the uncertainties, and possible damage to returns as a result of factors such as future additional regulated or subsidised interconnections (volume risk).

The variability of design in a hybrid scheme (e.g. narrow range v. wide range, symmetrical vs. asymmetrical ${ }^{25}$ ) shall depend on the specific market conditions. The primary risk to an investor of a hybrid scheme is a downside risk, similar to a merchant project, which occurs when a floor is set too low. However the specific characteristic of the "Mediterranean model" for a hybrid interconnector requires that this possible variability be reduced greatly by allocating a large fraction of the IC capacity to the winner of an open season ${ }^{26}$ process type auction for the available capacity. As opposed to the traditional schemes for open season auctions, here the winner will acquire long-term interconnection capacity ${ }^{27}$.

\footnotetext{
${ }^{23}$ The contract can be litigated in domestic or international courts based on the agreement between trading parties.

${ }^{24}$ The Association of Mediterranean Energy Regulators.

${ }^{25}$ Cap and Floor Regime for Regulation of Project NEMO and Future Subsea Interconnectors (Consultation published by Ofgem), Ref. 86/11 (28 June 2011).

${ }^{26}$ An open season is a procedure, common in gas interconnection capacity allocation mechanisms, where "a transparent and non-discriminatory call for binding commitments of any party for capacity is made by a group of TSOs together spanning two or more market areas, which may be preceded by non-binding expressions of interest of any party, in order to base an investment decision for a capacity expansion on the obtained commitments". Definition from ACER (2013).

${ }^{27}$ This is qualitatively equivalent to installing additional capacity in North Africa.
}

Business model for cross-border interconnections in the Mediterranean basin 

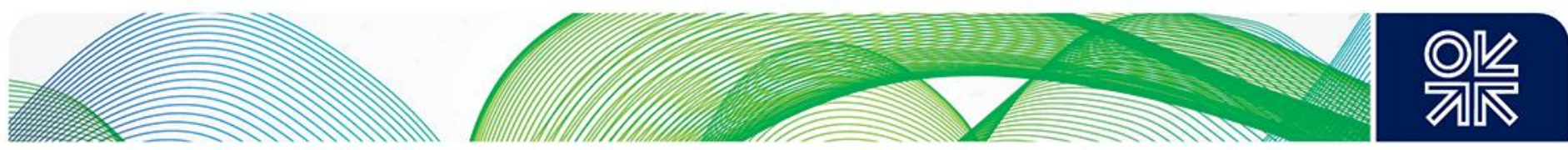

Figure 8: Med-TSO Interconnections in 2030

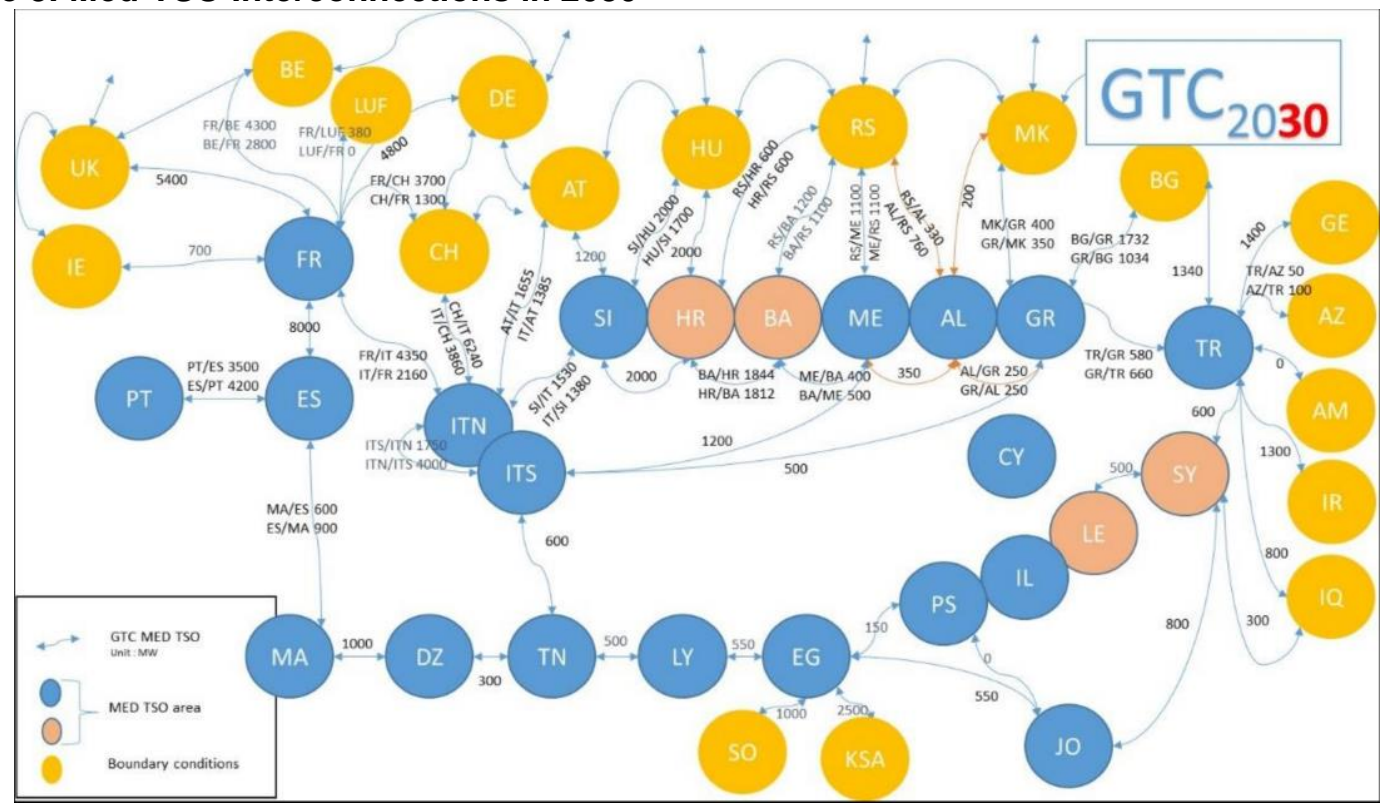

Source: Med-TSO 2015

In order to show the effectiveness of the hybrid model, we reconnect the main features of the model with the core market and regulatory aspects of investment incentive and efficient operation, risks and uncertainties as well as planning and governance.

Investment incentive and efficient operation -Investment incentives could be hampered in a purely competitive market framework where mainly price differentials provide investment signals. This is specifically important to North African countries where electricity markets are dominated by vertically integrated utilities and heavily subsidised electricity prices. Therefore, the first best theoretical solution is incompatible with the institutional framework that exists in the region. In order to make a feasible use of the proposed hybrid approach, the regulators involved in the approval process may need to relax the restrictions on unbundling (so a vertically integrated monopoly can become connected) and transit country issues. We envision that the interconnection will be developed with the vertically integrated utilities in the import node, and only purely as a back-to-back line. This model, while not currently foreseen by the EU regulation, has been adopted in the past for many years between importing and exporting countries in Europe ${ }^{28}$.

Risks and uncertainties - The proposed hybrid model sterilises most of the risk factors identified in section 5.2 (except perhaps those related to political instability and security risks). It reduces market and regulatory risks by adopting a long-term contract and is subject to some sort of fuel price indexation. The proposed contract will also include a take or pay provision that delivers a low risk (and low return) environment which better suits the typical TSO operational model. However, with the proposed hybrid

\footnotetext{
${ }^{28}$ Most interconnections in Europe have been designed as regulated lines where the capacity was assigned through long-term contracts. For example, this has been the case between Italy and France, see Brunekreeft, et al (2005), and also represents the current arrangement for the interconnector between Italy and Montenegro. Under an inter-governmental agreement signed in February of 2010 , the Italy-Montenegro interconnector plans to reserve $80 \%$ of its capacity for the Italian market. The project was included in the National Electricity Transmission Grid in December of 2009. Refer to the TYDP 2015, TERNA (Italian TSO) available here (in Italian): http://www.autorita.energia.it/allegati/operatori/pds/PdS\%202015 Gennaio\%202015.pdf
}

Business model for cross-border interconnections in the Mediterranean basin 

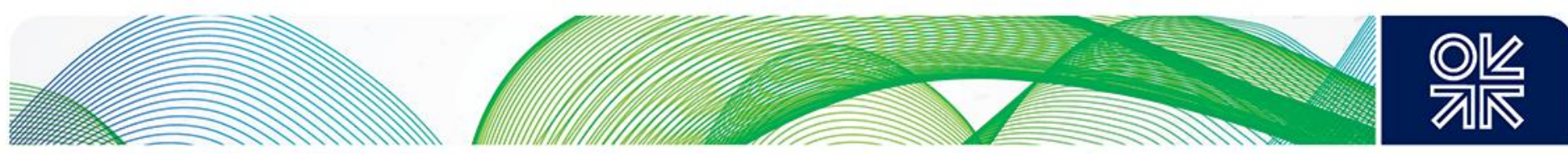

approach, the IC will still be subject to project-specific risks that need to be factored in when defining the long term remuneration associated with the project.

Planning and governance - The proposed Mediterranean interconnector model can be part of the "Master Plan of the Mediterranean Electricity Interconnections" that is currently being developed by Med-Tso ${ }^{29}$. The Master Plan responds to the need to coordinate the interconnection projects and interconnected grid operation at a regional level, and also develop international electricity exchanges in the Mediterranean basin. Under Med-Tso supervision, the proposed IC hybrid model could represent a viable benchmark for future cross-border lines, and establish the definition of the minimal economic and regulatory conditions that facilitates the development of additional lines planned in the region in the coming years. This model doesn't require a revision of the regulatory framework in place in both the exporting (EU) and importing countries (North Africa). It mainly reflects the existing market instruments and is coherent with the business model defined for the development of other energy infrastructure projects such as gas. For gas transportation, which has been developed in the region in the past, the difference in the market model and regulatory framework among the involved countries was overcome with an ad-hoc approach.

Beside its geographic specificity, the Mediterranean region has a strong institutional and regulatory peculiarity where national and regional interest and influence overlap and co-exist (Del Sarto and Steindler, 2015). In this region, EU, MS and SEMCs interest and influence often come to collide and energy cooperation is no exception to this general rule. The obstacles created by strong normative EU regulations have to some degree hampered the development of joint electricity interconnectors ${ }^{30}$.

Therefore, while there are merits in having a harmonised regulatory framework for the Mediterranean region, we also consider that an important task of regulation is to deal with imperfect markets and develop innovative solutions to address market failures. Certainly, having fully-fledged liberalised markets on both sides of the Mediterranean basin would greatly reduce system costs and improve the business climate. However, second and third best solutions can, at least partially, reduce market failures and help to create the conditions for market dynamics to emerge. A reasonable objective in this direction would be to identify the best combination of regulation and competition that favours consumers and paves the way for market opening and integration. The hybrid model discussed in this paper can overcome many of the concerns prevailing in the polar opposite business models and is more compatible with the nature of electricity systems and institutions in the Mediterranean region. Table 5 summarises the main features and also compatibility of the three business models (regulated, MTI and hybrid) with the governance structure and the risk attitude in the region.

This model could be directly applied to the development of an electricity interconnector linking the grids of Italy and Tunisia. The planned interconnector ("ELMED ${ }^{31 ")}$ will consist of a $1000 \mathrm{MW}$ high-voltage direct current (HVDC) line connected to either country via terminals in Partanna (Sicily) and El Hawaria (Tunisia). Terna will develop the interconnector in cooperation with STEG, the national utility company in Tunisia. In March 2009, Terna and STEG executed a partnership agreement to develop the line. However, since then the project has stalled.

\footnotetext{
${ }^{29}$ In 2013, Med-TSO - the Association of Mediterranean TSOs - started its activity. Med-TSO includes electricity companies operating the grids of 17 Mediterranean Countries.

${ }^{30}$ An overview of the recent development can be found in Cambini and Rubino (2014).

${ }^{31}$ ELMED Etudes Sarl is an entity formed jointly by Terna and STEG to manage "all preliminary activities" of the proposed interconnector. The interconnector will be developed by Terna in cooperation with STEG, the national utility company in Tunisia. In March of 2009, Terna and STEG executed a partnership agreement to develop the line. In addition, a Memorandum of Understanding has been executed by the Italian "Ministero della Tutela del Territorio e del Mare," the Tunisian "Ministère de l'Industrie et de la Technologie - Direction Générale de l'Energie" and the Tunisian "Agence Nationale pour la Maîtrise de l'Energie" in connection with Project ELMED.
}

Business model for cross-border interconnections in the Mediterranean basin 

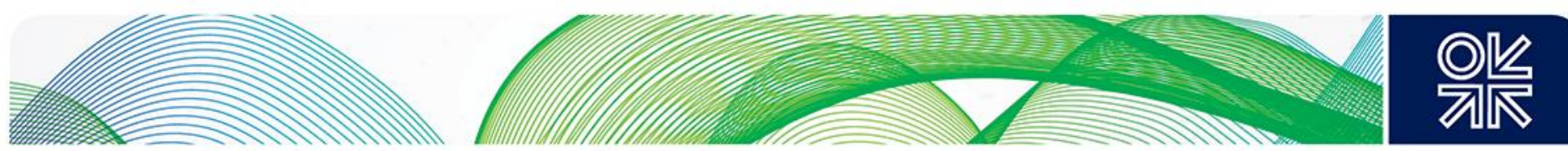

ELMED will be the first electricity interconnector linking Italy to North Africa. The proposed use of longterm contracts within a Regulated Investment Scheme presents a challenge; however, it is conceivable that regulators would approve their use for ELMED. While long-term contracts are generally seen as perilous to objective and non-discriminatory third party access, the current regulatory framework does not prohibit per se the use of long-term contracts for the allocation of interconnector capacity. Instead, long-term contracts may be permitted by national regulators and the Commission where their use is "compatible with Community law and consistent with Community policies." 32 The main objection on the part of regulators to the use of long-term contracts is the possibility that priority or preference would be granted to incumbents or dominant parties, which could have the effect of foreclosing the market for new entrants. Consequently, the design of the open season process must be carefully vetted to ensure objective and non-discriminatory access to third parties. An auction procedure that is well designed to permit access to third parties in compliance with the EU regulatory framework significantly increases the likelihood that regulators will approve long-term capacity contracts.

\footnotetext{
${ }^{32}$ Article 37(1)(I) of Regulation (EC) No 714/2009 and Regulation (EC) No 1228/2003.
}

Business model for cross-border interconnections in the Mediterranean basin 

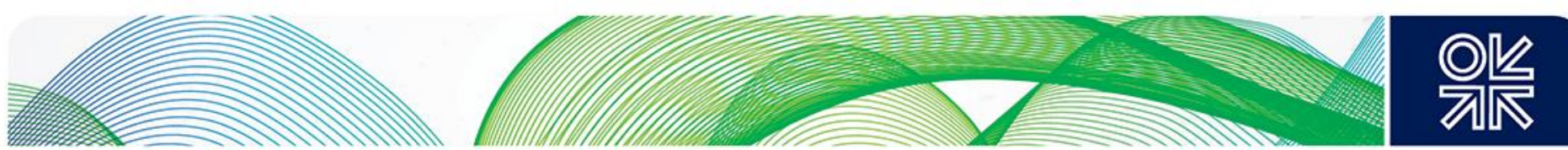

Table 5: Advantages and disadvantages of investment models in interconnections

\begin{tabular}{|c|c|c|c|c|}
\hline & Ownership & Primary Benefits & $\begin{array}{c}\text { Primary } \\
\text { Disadvantages }\end{array}$ & EU Examples \\
\hline Merchant Line & $\begin{array}{c}\text { x Private Investors } \\
\text { or indirect } \\
\text { ownership by a } \\
\text { TSO via a Legally } \\
\text { separate entity }\end{array}$ & $\begin{array}{l}\text { Exemption from } \\
\text { regulatory } \\
\text { framework: } \\
\checkmark \text { No restrictions on } \\
\text { use of congestion } \\
\text { revenues, i.e. more } \\
\text { control over debt } \\
\text { amortization } \\
\checkmark \text { No regulated } \\
\text { third party access, } \\
\text { i.e. Investor may } \\
\text { reserve capacity } \\
\text { for own use }\end{array}$ & $\begin{array}{c}x \text { Investors absorb } \\
\text { losses with no } \\
\text { recourse to } \\
\text { transmission tariffs } \\
\text { paid by customers } \\
\text { xFinancing must } \\
\text { be obtained by } \\
\text { Developer }\end{array}$ & $\begin{array}{c}\text { EstLink } \\
\text { BritNed } \\
\text { Imera } \\
\text { Tarvisio }\end{array}$ \\
\hline Regulated Line & $\begin{array}{l}\checkmark \text { TSO owns } \\
\text { directly }\end{array}$ & $\begin{array}{l}\checkmark \text { Predetermined } \\
\text { rate-of-return } \\
\text { incentivizes } \\
\text { investment by } \\
\text { TSOs }\end{array}$ & $\begin{array}{c}\checkmark \text { Congestion } \\
\text { revenues are } \\
\text { capped } \\
\times \text { Penalties for } \\
\text { failure to provide } \\
\text { allocated capacity } \\
\text { ×Access must be } \\
\text { granted objectively } \\
\text { and without } \\
\text { discrimination }\end{array}$ & $\begin{array}{l}\text { NorNed } \\
\text { IFA }\end{array}$ \\
\hline $\begin{array}{c}\text { Mediterranean } \\
\text { Model }\end{array}$ & $\begin{array}{l}\checkmark \text { TSO owns } \\
\text { directly }\end{array}$ & $\begin{array}{c}\checkmark \text { Losses are } \\
\text { collared, i.e. if they } \\
\text { fall below set } \\
\text { levels, they will be } \\
\text { socialized via } \\
\text { higher transmission } \\
\text { tariffs paid by } \\
\text { customers in the } \\
\text { EU }\end{array}$ & $\begin{array}{c}\checkmark \text { Prices are } \\
\text { capped as they } \\
\text { would be under a } \\
\text { regulated regime } \\
\checkmark \text { Power supply is } \\
\text { subject to long } \\
\text { term contract } \\
\checkmark \text { Take or pay } \\
\text { clause is also } \\
\text { included in the } \\
\text { contractual } \\
\text { arrangement }\end{array}$ & / \\
\hline
\end{tabular}

Degree of compatibility with the governance structure and the attitude toward risk in the region

$\times$ Not compatible, $\checkmark$ Compatible 

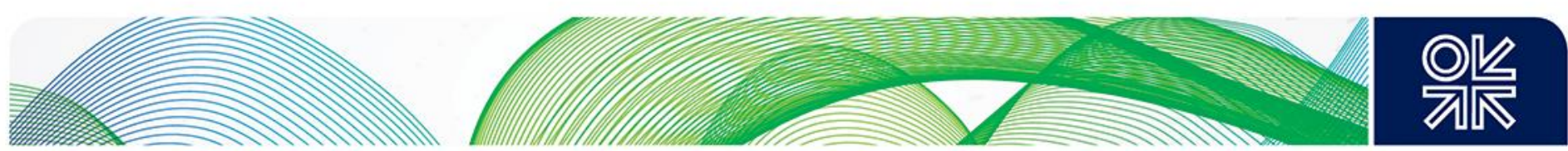

\section{Conclusions and policy implications}

In order to achieve national and regional energy policy objectives, cross-border interconnections in the Euro-MENA region need to be considerably enhanced. Although the disparities among the NMECs and SEMCs countries in terms of the stage of market development, regulations, energy policy objectives and priorities make development of interconnections challenging, both sides of the basin would benefit from more interconnected electricity systems. The SEMCs can meet their increasing electricity demand and improve their security of electricity supply, while NMCs can promote the sustainability and efficiency of their electricity systems. This paper analysed the development of cross-border interconnections in the Mediterranean basin in order to highlight the challenges of current investment models and shed light on the specifications of a viable business model.

A viable business model for the Mediterranean region needs to address the issues related to: (i) investment incentive and efficient operation (ii) management of risk and uncertainties and (iii) coordinated planning and governance. The regulated investment, as the main business model for interconnections in the EU region, has failed to deliver the required investment. The merchant transmission initiative, which is seen as an exception under the EU laws, is allowed only when the investor can prove that the risk is so high that under the regulated model investment will not take place. Due to the presence of heterogeneities among the EU and Non-EU countries, the application of polar models (regulated and merchant transmission initiative) are problematic. Therefore, we advocate a hybrid business model in which the main benefits of a merchant model are maintained within a regulated structure. We highlight the main component of the proposed business model and show how it addresses the key features of a viable business model in relation to incentives, risks and governance. The model assumes interconnections will initially be developed to export excess electricity capacity from Europe to North Africa, but it is compatible with any development of the regions' electricity mix in the future, especially the eventual export of renewble power from north Africa to Europe. Furthermore, the suggested business model operates with minimum requirement of change in the regulations of the domestic markets. Therefore, it can better incentivise investment and is more compatible with the region's governance structures and risk attitude. 

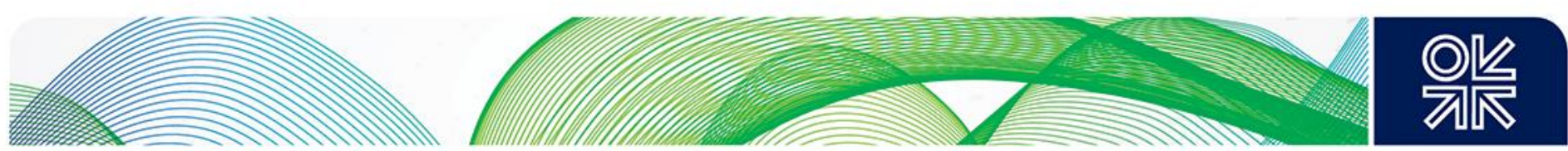

\section{References}

ACER, 2013. Guidance to ENTSOG on the Development of Amendment Proposals to the Network Code on Capacity Allocation Mechanisms on the Matter of Incremental and New Capacity. ACER, Lubjana.

Brunekreeft, G. (2004) "Market-based investment in electricity transmission networks: controllable flow" Utilities Policy 12: 269-281.

Brunekreeft, G. (2005) "Regulatory issues in merchant transmission investment" Utilities Policy 13: 175-186.

Brunekreeft,G., Neuhoff, K. and Newbery, D. (2005) "Electricity transmission: An overview of the current debate" Utilities Policy 13: 73-93.

Bushnell, J.B., Stoft, S.E., (1996)" Electric grid investment under a contract network regime" Journal of Regulatory Economics 10, 61-79.

Cambini, C., Rubino, A., EU Pressures and Institutions for Future Mediterranean Energy Markets: Evidence from a Perception Survey, In Regulation and Investments in Energy Markets, edited by Alessandro Rubino et al., Academic Press, 2016, Pages 133-153, ISBN 9780128044360 , http://dx.doi.org/10.1016/B978-0-12-804436-0.00008-4.

de Hauteclocque, A. and Rious, V. (2011) "Reconsidering the European regulation of merchant transmission investment in light of the third energy package: The role of dominant generators" Energy Policy 39: 7068-7077.

Del Sarto, R., and Steindler, C. (2015) Uncertainties at the European Union's southern borders: actors, policies, and legal frameworks, European Security, 24:3, 369-380, DOI:

10.1080/09662839.2015.1028184.

Dii. (2012) "Perspectives on a sustainable power system for EUMENA", Dii Report.

El-Katiri, L. and Fattouh,B. (2015), A Brief Political Economy of Energy Subsidies in the Middle East and North Africa, OIES PAPER: MEP 11.

Escribano, G., Convergence towards Differentiation: The Case of Mediterranean Energy Corridors, Mediterranean Politics , 15 (2), 2010

EU (2009), "Regulation (EC) No 714/2009 of the European Parliament and of the Council, on conditions for access to the network for cross-border exchanges in electricity and repealing Regulation (EC) No 1228/2003, Official Journal of European Union, 14 August 2009.

Franz Trieb, Marlene O'Sullivan, Thomas Pregger, Christoph Schillings, Wolfram Krewitt (2009), Characterisation of Solar Electricity Import Corridors from MENA to Europe. Potential, Infrastructure and Cost. German Aerospace Center (DLR), Stuttgart, Germany

Frayer. J. (2013) "Merchant transmission: planning and development Lessons Learned from North America", presentation in Integrated Transmission Planning and Regulation (ITPR) conference 11 January, Imperial College, London. https://www.ofgem.gov.uk/ofgem-publications/52767/januaryworkshop-julia-frayer-london-economics-international.pdf.

Habib El Andaloussi (2010) 'Infrastructures and Sustainable Energy Development in the Mediterranean', Plan Bleu

Hogan, W., Rosellón, J. and Vogelsang, I. (2010) "Toward a combined merchant-regulatory mechanism for electricity transmission expansion". Journal of Regulatory Economics 38:113-143.

Hogan, W.W., (1992) "Contract networks for electric power transmission" Journal of Regulatory Economics 4: 211-242. 

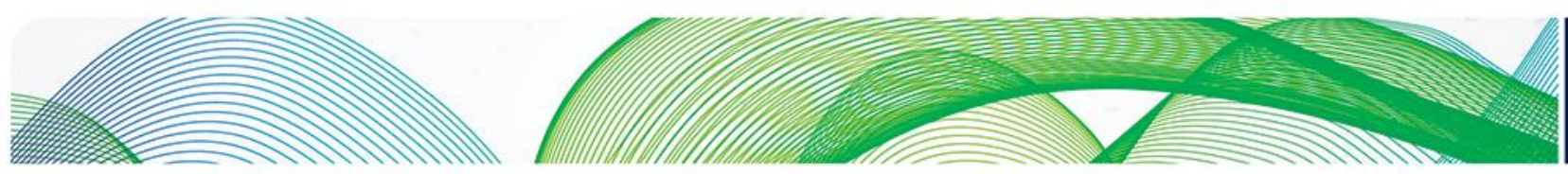

Joskow, P (1988), Asset Specificity and the Structure of Vertical Relationships: Empirical Evidence, Journal of Law, Economics, \& Organization, Vol. 4, No. 1 (Spring, 1988), pp. 95-117

Joskow, $\mathrm{P}$ (2005). "Patterns of transmission investment", Electricity infrastructure investment workshop, Paris, France: CRE March 15.

Khalfallah, H., 2015. Connecting Mediterranean countries through electricity corridors: new institutional economic and regulatory analysis. Utilities Policy 32, 45-54.

Kapff, L. and Pelkmans, J. (2010) "Interconnector Investment for a Well-Functioning Internal Market: What EU regime of regulatory incentives? Bruges European Economic Research (BEER) Papers 18/October 2010. https://www.coleurope.eu/system/files_force/research-

paper/beer18.pdf?download=1.

L'Abbate, A ., Migliavacca, G., Calisti, R., Brancucci Martinez-Anido, C., Aymen, C., \& Fulli, G. (2014). Electricity exchanges with North Africa at 2030, the European and the Italian approach. In C. Cambini, \& A. Rubino, Regional Energy Initiatives. MedReg and the Energy Community (pp. 225-45). London: Routledge.

Littlechild, S. (2011), "Merchant and regulated transmission: theory, evidence and policy", Journal of Regulatory Economics, 42:308-335.

Medgrid Project, http://www.medgrid-psm.com/.

MedReg, (2015) , Interconnection Infrastructures In The Mediterranean: A Challenging Environment For Investments. Consultation document. Available at http://www.medregregulators.org/Portals/45/questionnaire/Interconnection_Infrastructures_Report_Final.pdf Neuhoff, K., Boyd, R. and Glachant, J.M (2012), "European Electricity Infrastructure: Planning, Regulation, and Financing" Climate Policy Initiative Workshop Report, Available online: http://climatepolicyinitiative.org/wp-content/uploads/2012/01/EU-Grid-Workshop-Summary2012.01.25.pdf.

OME (2013), Observatoire Mediterranéèn de l'Energie . Mediterranean Energy Perspective. Paris: OME.

OME (2015), Observatoire Mediterranéèn de l'Energie . Mediterranean Energy Perspective. Paris: OME.

OJ(2009) "DIRECTIVE 2009/72/EC of the European Parliament and of the council of 13 July 2009 concerning common rules for the internal market in electricity and repealing Directive 2003/54/EC. Official Journal of European Union L211/55, 14 August, 2009.

REN21 (2013), MENA Renewable Status Report, Paris, REN21 Secretariat. Publiaction available at the following link:

http://www.ren21.net/Portals/0/documents/activities/Regional\%20Reports/MENA_2013_lowres.pdf

Rubino, A. (2014). A Mediterranean electricity cooperation strategy. Vision and rationale. In C.

Cambini, \& A. Rubino, Regional Energy Initiatives. MedReg and the Energy Community (pp. 31-44). London: Routledge.

Rubino, A. and Cuomo, M., (2015), A regulatory assessment of the Electricity Merchant Transmission Investment in EU, Energy Policy, Volume 85, October 2015, Pages 464-474, ISSN 0301-4215, http://dx.doi.org/10.1016/j.enpol.2015.06.033.

Tholens, S. (2014), An EU-South Mediterranean Energy Community: The Right Policy for the Right Region?, The International Spectator, Vol. 39, No 2.

von Hirschhausen, C. (2011) "Financing Trans-European Energy Infrastructures-Past, Present and Perspectives" available online: http://www.notre-europe.eu/media/c.vonhirschhausen-

energyinfrastructures-notre-europe-nov2011.pdf?pdf=ok. 

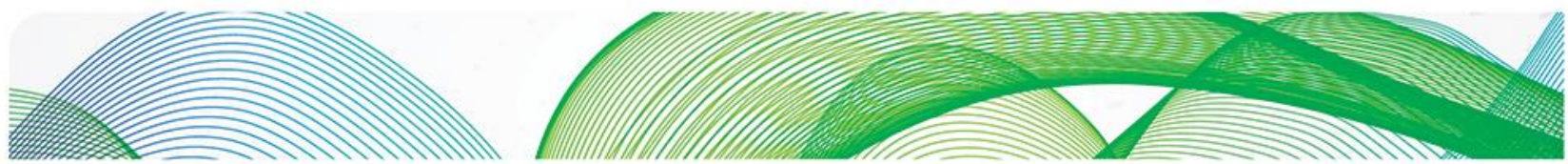

\section{OVI}

Vantaggiato, F.P. (2016). Defining Euro-Mediterranean Energy Relations, In Regulation and Investments in Energy Markets, edited by Alessandro Rubino et al., Academic Press, 2016, Pages 23-40, ISBN 9780128044360, http://dx.doi.org/10.1016/B978-0-12-804436-0.00002-3. 
Table A1: Existing interconnections in SEMCs

\begin{tabular}{|c|c|c|c|c|c|}
\hline From country & To & $\begin{array}{c}\text { Voltage } \\
\text { level }\end{array}$ & $\begin{array}{l}\text { Line capacity } \\
\text { (nominal) }\end{array}$ & Financing method & $\begin{array}{c}\text { Starting } \\
\text { year }\end{array}$ \\
\hline \multirow[t]{8}{*}{ Algeria } & \multirow{3}{*}{ Morocco } & $225 \mathrm{kV}$ & $150 \mathrm{MW}$ & -- & 1988 \\
\hline & & 225 kV & $190 \mathrm{MW}$ & -- & 1988 \\
\hline & & $400 \mathrm{kV}$ & 1200 MVA & -- & 2010 \\
\hline & \multirow[t]{5}{*}{ Tunisia } & $90 \mathrm{kV}$ & $180 \mathrm{MW}$ & -- & 1952 \\
\hline & & $90 \mathrm{kV}$ & $200 \mathrm{MW}$ & -- & 1955 \\
\hline & & 225 kV & 1200 MVA & -- & 1980 \\
\hline & & 150 kV & & -- & 1984 \\
\hline & & $220 \mathrm{kV}$ & & -- & 2010 \\
\hline \multirow[t]{3}{*}{ Egypt } & Libya & 220 kV & $120 \mathrm{MW}$ & \multirow[t]{3}{*}{ Public Finance } & 1998 \\
\hline & Jordan & 400 kV & $550 \mathrm{MW}$ & & 1998 \\
\hline & Palestine & $22 \mathrm{kV}$ & $21 \mathrm{MW}$ & & 2008 \\
\hline \multirow[t]{3}{*}{ Jordan } & Egypt & 400 kV & 550 MVA & Public Line & 1998 \\
\hline & & & & $\begin{array}{c}\text { (Grant from Arab } \\
\text { Fund) }\end{array}$ & \\
\hline & Syria & $400 \mathrm{kV}$ & 1000 MVA & & 1998 \\
\hline \multirow[t]{3}{*}{ Libya } & Egypt & \multirow[t]{3}{*}{220 kV } & $120 \mathrm{MW}$ & \multirow{3}{*}{$\begin{array}{l}\text { Government } \\
\text { Funding }\end{array}$} & 1998 \\
\hline & Tunisia & & $200 \mathrm{MW}$ & & 2003 \\
\hline & & & & & 2003 \\
\hline \multirow[t]{3}{*}{ Morocco } & \multirow[t]{3}{*}{ Algeria } & 225 kV & $150 \mathrm{MW}$ & -- & 1988 \\
\hline & & $225 \mathrm{kV}$ & $190 \mathrm{MW}$ & -- & 1988 \\
\hline & & $400 \mathrm{kV}$ & 1200 MVA & -- & 2010 \\
\hline Palestine & Egypt & $22 \mathrm{kV}$ & $17 \mathrm{MW}$ & Public & 2008 \\
\hline \multirow[t]{6}{*}{ Tunisia } & Libya & $225 \mathrm{kV}$ & $200 \mathrm{MW}$ & -- & 2003 \\
\hline & \multirow[t]{5}{*}{ Algeria } & $90 \mathrm{kV}$ & $180 \mathrm{MW}$ & -- & 1952 \\
\hline & & $90 \mathrm{kV}$ & $200 \mathrm{MW}$ & -- & 1955 \\
\hline & & 225 kV & $1200 \mathrm{MW}$ & -- & 1980 \\
\hline & & $150 \mathrm{kV}$ & & -- & 1984 \\
\hline & & 220 kV & & -- & 2010 \\
\hline
\end{tabular}

Source: NRAs data, MedReg consultation (2015) 